ARTICLE

\title{
An acid-tolerance response system protecting exponentially growing Escherichia coli
}

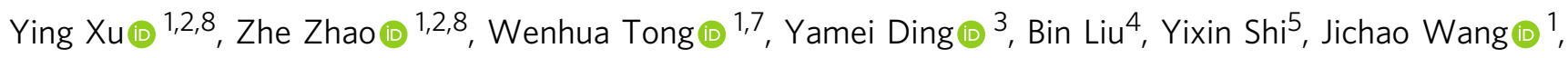
Shenmei Sun ${ }^{1,2}$, Min Liu (1D ${ }^{1}$, Yuhui Wang ${ }^{4}$, Qingsheng $\mathrm{Qi}^{6}$, Mo Xian ${ }^{1 凶}$ \& Guang Zhao (1) ${ }^{1,6 \times}$

The ability to grow at moderate acidic conditions ( $\mathrm{pH} 4.0-5.0)$ is important to Escherichia coli colonization of the host's intestine. Several regulatory systems are known to control acid resistance in E. coli, enabling the bacteria to survive under acidic conditions without growth. Here, we characterize an acid-tolerance response (ATR) system and its regulatory circuit, required for $E$. coli exponential growth at $\mathrm{pH}$ 4.2. A two-component system CpxRA directly senses acidification through protonation of CpxA periplasmic histidine residues, and upregulates the $f a b A$ and $f a b B$ genes, leading to increased production of unsaturated fatty acids. Changes in lipid composition decrease membrane fluidity, $\mathrm{F}_{0} \mathrm{~F}_{1}$-ATPase activity, and improve intracellular $\mathrm{pH}$ homeostasis. The ATR system is important for $E$. coli survival in the mouse intestine and for production of higher level of 3-hydroxypropionate during fermentation. Furthermore, this ATR system appears to be conserved in other Gram-negative bacteria.

\footnotetext{
${ }^{1}$ CAS Key Lab of Biobased Materials, Qingdao Institute of Bioenergy and Bioprocess Technology, Chinese Academy of Sciences, 266101 Qingdao, China. ${ }^{2}$ University of Chinese Academy of Sciences, 100049 Beijing, China. ${ }^{3}$ Institute of Oceanology, Chinese Academy of Sciences, 266071 Qingdao, China.

${ }^{4}$ TEDA Institute of Biological Sciences and Biotechnology, Nankai University, TEDA, 300457 Tianjin, China. ${ }^{5}$ School of Life Sciences, Arizona State University, Tempe, AZ 85281, USA. ${ }^{6}$ State Key Laboratory of Microbial Technology, Shandong University, 266237 Qingdao, China. ${ }^{7}$ Present address: Sichuan University of Science and Engineering, 644000 Yibin, Sichuan, China. ${ }^{8}$ These authors contributed equally: Ying Xu, Zhe Zhao. ${ }^{凶}$ email: xianmo@gibebt.ac.cn; zhaoguang@qibebt.ac.cn
} 
E nteric bacteria such as Escherichia coli (E. coli) and Salmonella can colonize and cause disease in the human intestinal tract. They have to combat acidic environments during the whole process of invading the host. With $\mathrm{pH}$ values as low as 1.5-2.5, the stomach has been recognized as a natural antibiotic barrier ${ }^{1}$. With their passage into the small intestine, $E$. coli cells will encounter a less acidic environment ( $\mathrm{pH} 4.0-6.0)$ with the presence of organic acids produced by the normal intestinal flora ${ }^{2}$.

E. coli has developed variable acidic stress response systems, including the acid resistance (AR) systems response to extreme acid stress and the acid tolerance response (ATR) system towards mild and moderate acid stress ${ }^{3,4}$. Up to now, five AR systems, AR1-AR5, are reported. The AR1 system is activated by alternative $\sigma$ factor (RpoS) and cAMP receptor protein $(\mathrm{CRP})^{5,6}$. Due to the involvement of CRP, the AR1 system is repressed by glucose. The AR2-AR5 systems are all dependent on a specific extracellular amino acid, and consist of an antiporter as well as a decarboxylase enzyme that is usually induced by low $\mathrm{pH}$ and extracellular amino acid 3,7 , except that AR2 can be induced at acidic $\mathrm{pH}$ in the absence of glutamate ${ }^{8}$. They confer acid resistance by consumption of intracellular protons in amino acid decarboxylation reaction to produce a less acidic internal $\mathrm{pH}$, using glutamate, arginine, lysine and ornithine as their corresponding substrates, respectively ${ }^{1,5,9-12}$. All five AR systems can protect stationary phase cells from the extreme acidity and prolong survival, while only AR2 and AR3 were reported to function during the exponential phase $\mathrm{e}^{5,13}$.

Among AR systems, AR2 is by far the most effective and the most complex. The glutamate decarboxylase isoforms, GadA and $\mathrm{GadB}$, and the glutamate $/ \gamma$-aminobutyric acid antiporter GadC are key components of AR2, and their regulation relies on the action of over 20 proteins and 3 small noncoding RNAs, including two-component systems EvgAS and PhoPQ; regulatory proteins RpoS, GadE, RcsB, GadX, GadW and HNS; protease ClpXP and Lon; and small RNAs DsrA, GadY and GcvB, which together form a regulatory network with high level of complexity (for a review, see refs. ${ }^{3,7}$ ). The periplasmic chaperons HdeAB and their cytoplasmic counterpart Hsp31, which assist the refolding of denatured proteins during the acid stress $s^{7,14,15}$, are also induced as part of the AR2 regulon ${ }^{16,17}$.

The ATR system, though poorly understood, is induced by exposing E. coli cells to moderate acid stress ( $\mathrm{pH} 4.5-5.8$ ), and will protect cells from a subsequent challenge of extreme acid $\mathrm{pH}$ $(\mathrm{pH} 2.0-3.0)^{4,6}$. ATR can be activated during adaptation at mild acidic $\mathrm{pH}$ by the regulators Fur and PhoPQ in exponential phase cells and by RpoS and OmpR in stationary phase cells, but the stationary phase cells are much more tolerant to acid than the log phase cells ${ }^{3,4}$.

Benefited from the complicated AR and ATR systems, E. coli can survive without growth for several hours at $\mathrm{pH} 2.0^{1,18-20}$, and the acid limit for growth of $E$. coli is $\mathrm{pH} 4.0$ in rich medium, or $\mathrm{pH} 4.5$ in minimal medium ${ }^{6,18,20-22}$. So, E. coli will experience the transition of $\mathrm{pH}$ from no-growth to growth conditions when passing through the stomach and entering the intestine. It is exceptionally important to elucidate how E. coli adapts to and grows at $\mathrm{pH} 4.0-5.0$, because the capability of bacteria to outgrow hundreds of competing species in gut microbiome in this lower range of growth $\mathrm{pH}$ will determine which strain can colonize the gut $^{18}$. Unfortunately, we still barely know that.

In this study, we challenged the exponentially growing cells of

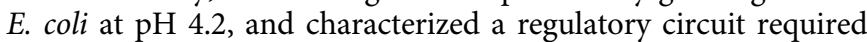
for bacterial growth under moderate acidic conditions through modulation of the membrane lipid composition. The twocomponent system CpxRA directly senses acidification through protonation of the CpxA periplasmic histidine residues, and thus activates transcription of the essential genes $f a b A$ and $f a b B$ in biosynthesis of unsaturated fatty acids (UFAs) to enhance the UFAs content in membrane lipid. This mechanism enables E. coli to grow at acidic $\mathrm{pH}$, and also functions in diverse bacterial species.

\section{Results}

UFAs are required for $\boldsymbol{E}$. coli growth under acidic $\mathbf{p H}$. We carried out a screening to characterize an E. coli ATR system required for bacterial survival in exponential growth. At first, the overnight culture of $E$. coli BW25113 wild-type strain was directly inoculated into minimal medium $\mathrm{E}$ at $\mathrm{pH} 4.2$ using glucose as sole carbon source without supplement of any amino acid. However, the cells were rapidly killed, even preadapted at pH 5.0 (Supplementary Fig. 1). Then the BW25113 strain was grown in medium $\mathrm{E}$ at $\mathrm{pH} 7.0$ to a cell density of $\approx 3 \times 10^{8} \mathrm{CFU} \mathrm{mL}^{-1}$, and the cells were collected, washed and transferred into the same medium at $\mathrm{pH} 7.0$ and 4.2, respectively. While the cells at $\mathrm{pH} 7.0$ grew normally, the cell density at $\mathrm{pH} 4.2$ decreased continuously, which led to reduction of the ratio of $\mathrm{CFU}$ at $\mathrm{pH} 4.2$ vs. $\mathrm{pH} 7.0$ to $0.21 \pm 0.02$ after $1 \mathrm{~h}$ of exposure at different $\mathrm{pH}$ (Fig. 1a). This result confirmed that exponentially growing $E$. coli was susceptible to this moderate acidic condition.

In previous studies, survival was used to measure the bacterial acid resistance, which is calculated by the formula, survival (\%) $=$ (CFU after acid challenge/CFU before acid challenge) $\times 100 \%$. However, survival was determined under conditions $E$. coli can only survive without growth, and is not suitable here as we are trying to figure out how E. coli grows at moderate acidic $\mathrm{pH}$. So, the CFU ratio ( $\mathrm{pH} 4.2 / \mathrm{pH} 7.0$ ) is calculated to represent the acid tolerance of exponentially growing $E$. coli because growth of $E$. coli at pH 7.0 is steady. A value of CFU ratio close to 1 indicates that $E$. coli grows at $\mathrm{pH} 4.2$ to a cell density similar to that at $\mathrm{pH} 7.0$.

Phospholipids were extracted from exponential phase cells after exposure of $1 \mathrm{~h}$ to $\mathrm{pH} 7.0$ and 4.2, and analyzed as previously described ${ }^{23}$. The results showed that exposure to such acidic condition caused a change of membrane lipid composition in E. coli cells (Fig. 1b). Specifically, levels of the UFAs, including palmitoleic acid (C16:1) and oleic acid (C18:1), were elevated by 3.83- and 1.66-fold; meanwhile, the levels of palmitic acid (C16:0) and stearic acid (C18:0) were reduced. These five fatty acids shown in Fig. 1 b represented more than $96 \%$ of total fatty acids in E. coli cells, consistent with those results reported previously ${ }^{24,25}$. As a consequence, the ratio of unsaturated to saturated fatty acids increased from 0.11 at $\mathrm{pH} 7.0$ to 0.32 at $\mathrm{pH}$ 4.2. Comparable to this result in E. coli, a shift in the unsaturated/saturated ratio in response to acid stress was also observed in Streptococcus mutants $^{26,27}$.

We also found that the expression of two essential genes required for UFAs biosynthesis, $f a b A$ and $f a b B$ (Fig. 1c), was significantly upregulated under the acidic condition since their protein and mRNA levels were elevated (Fig. 1d, e). A previous study showed that overexpression of $f a b A$ and $f a b B$ increased UFA contents in $E$. coli ${ }^{28}$. Therefore, it is plausible that overexpression of $f a b A$ and $f a b B$ may allow $E$. coli to grow under $\mathrm{pH}$ 4.2. To test this hypothesis, we cloned $f a b A$ and $f a b B$ into vector pTrcHis2B, and introduced them into BW25113 wild-type strain. The strain carrying empty vector presented a CFU ratio of $0.26 \pm 0.03$, similar with that of BW25113 wild-type strain, while either strain with $f a b A$ or $f a b B$ showed much higher acid tolerance at $\mathrm{pH} 4.2$ (Fig. 1f).

In agreement with this result, strains harboring a temperaturesensitive mutant of $f a b A$ or $f a b B$ gene became much more susceptible to acid at $42^{\circ} \mathrm{C}$, whereas the wild-type strain showed 

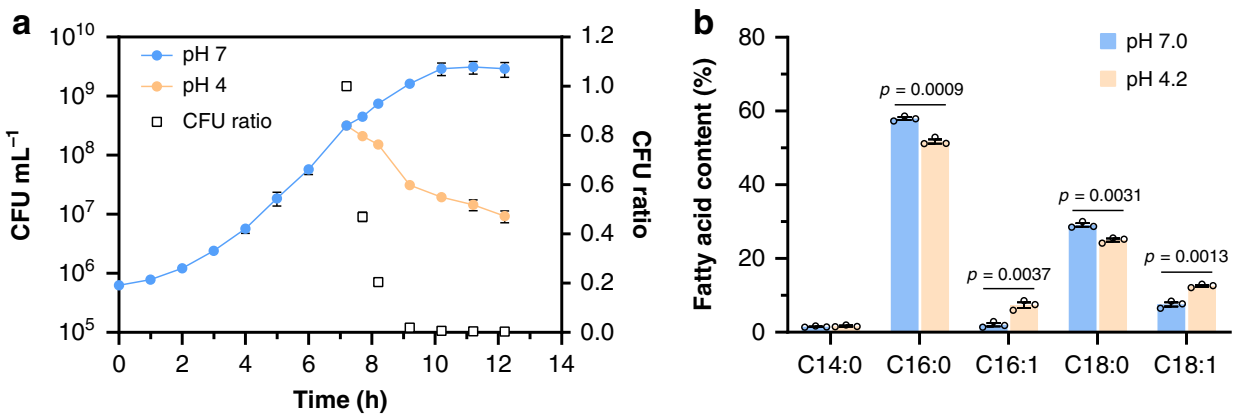

C

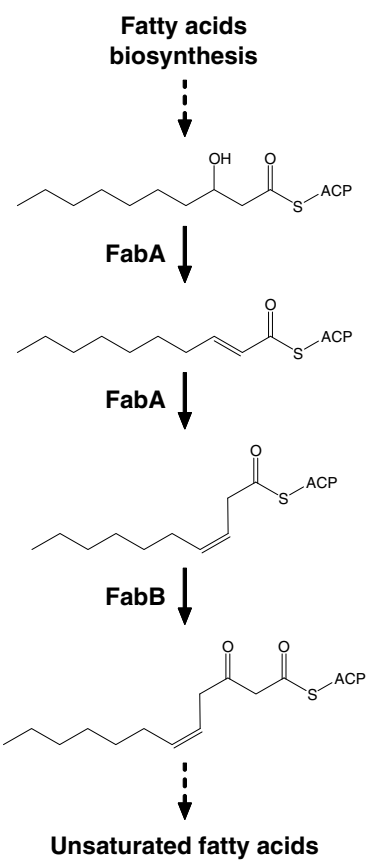

d
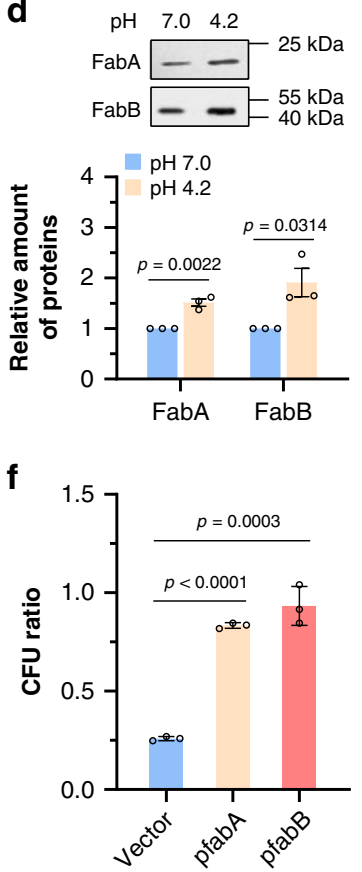
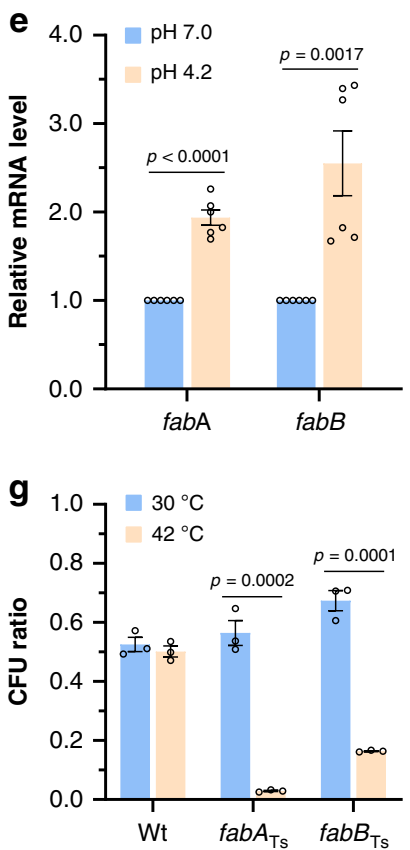

Fig. 1 Improved acid tolerance of exponentially growing $E$. coli caused by increased production of unsaturated fatty acids. a Growth of $E$. coli BW25113 strain at different $\mathrm{pH}$. The strain was grown to $3 \times 10^{8} \mathrm{CFU} \mathrm{mL}-1$ in minimal medium at $\mathrm{pH} 7.0$, and transferred into the same medium at $\mathrm{pH} 7.0$ and $\mathrm{pH} 4.2$ ( $n=3$ biologically independent samples). CFU ratio $=\mathrm{CFU}$ at $\mathrm{pH} 4.2 / \mathrm{CFU}$ at $\mathrm{pH}$ 7.0. b Membrane lipid composition of BW25113 strain after acidic challenge at $\mathrm{pH} 4.2$ for $1 \mathrm{~h}$. The compositions were determined by GC-MS, and fatty acid content is given as the relative peak area [(peak area of one fatty acid/total peak area) $\times 100 \%]$ ( $n=3$ biologically independent samples). c Biosynthetic pathway of unsaturated fatty acids, in which FabA and FabB, 3-hydroxyacyl-ACP dehydratase/isomerase and $\beta$-ketoacyl-ACP synthase play essential roles. d FabA-His 6 and FabB-His 6 protein level of BW25113 strain after $1 \mathrm{~h}$ of exposure to $\mathrm{pH} 7.0$ and 4.2 determined by western blot. The relative amount of each protein was determined using Image $(n=3$ biologically independent samples). e Relative mRNA level of $f a b A$ and $f a b B$ in BW25113 strain after $1 \mathrm{~h}$ of exposure to pH 7.0 and 4.2 determined by qRT-PCR ( $n=2$ biologically independent samples with three technical repeats). f Tolerance of BW25113 strain carrying empty vector pTrcHis2B, pfabA or pfabB, respectively, after acidic challenge at $\mathrm{pH} 4.2$ for $1 \mathrm{~h}$ ( $n=3$ biologically independent samples). $\mathbf{g}$ Tolerance of BW25113 strain, temperature-sensitive FabA and FabB mutants after acidic challenge at $\mathrm{pH} 4.2$ at 30 or $42^{\circ} \mathrm{C}$ for $0.5 \mathrm{~h}$ ( $n=3$ biologically independent samples). Error bars, mean \pm standard error of mean (SEM). Two-tailed Student's $t$ tests were performed to determine the statistical significance for two group comparisons. The source data are provided as a Source Data file.

similar acid tolerance at different temperatures (Fig. 1g). Taken together, these results demonstrated that elevating the biosynthesis of UFAs enhanced the acid tolerance of exponentially growing E. coli.

Transcription of $f a b A$ and $f a b B$ is activated by CpxRA system. To find out the possible regulator of these loci, we compared the DNA sequences of $f a b A$ and $f a b B$ promotor regions, and found a conserved sequence GTAAA-(5 nt)-GCAAA (Fig. 2a, b), which was similar to the identified CpxR recognition site ${ }^{29}$. This raised the hypothesis that the transcription of $f a b A$ and $f a b B$ is regulated by two-component system CpxRA, which consists of a sensor histidine kinase CpxA and a cytoplasmic response regulator
CpxR. Since overexpression of outer membrane protein NlpE was identified as a Cpx-specific activation signal ${ }^{30,31}$, we cloned the $n l p E$ gene and tested its effect on expression of $f a b A$ and $f a b B$ loci. As shown in Fig. 2c, d, excessive NlpE protein significantly enhanced the expression level of $f a b A$ and $f a b B$ at $\mathrm{pH}$ 7.0, and deletion of $c p x R$ totally abolished this activating effect of NlpE. Besides those, NlpE overexpression also raised the UFAs content in E. coli membrane lipid at pH 7.0 (Fig. 2e) and E. coli acid tolerance at $\mathrm{pH} 4.2$ (Fig. 2f) in a CpxR-dependent manner since $c p x R$ knockout mutant displayed higher susceptibility to acidic challenge than wild-type strain even overexpressing NlpE (Fig. 2f). These observations collectively demonstrate that the CpxRA system activates transcription of $f a b A$ and $f a b B$. 
$\mathbf{a}$
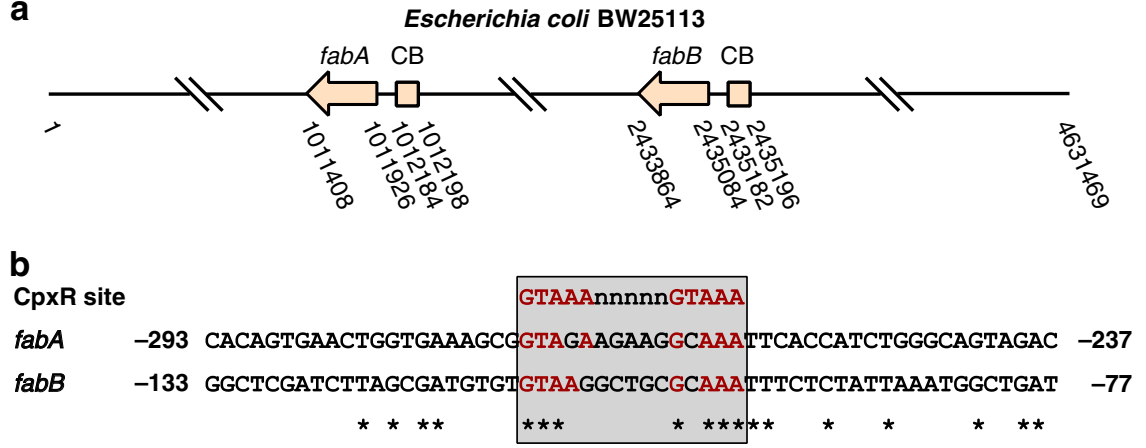

C

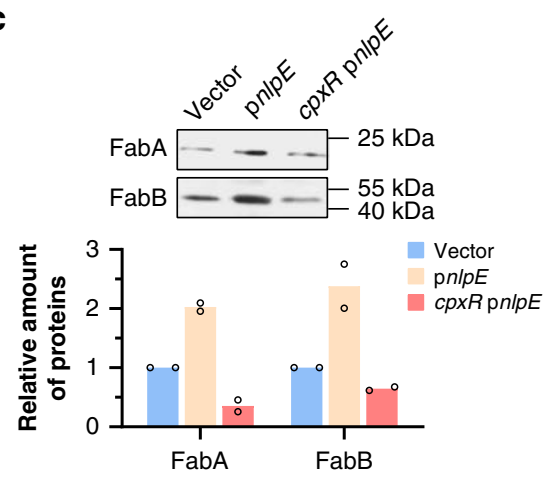

e

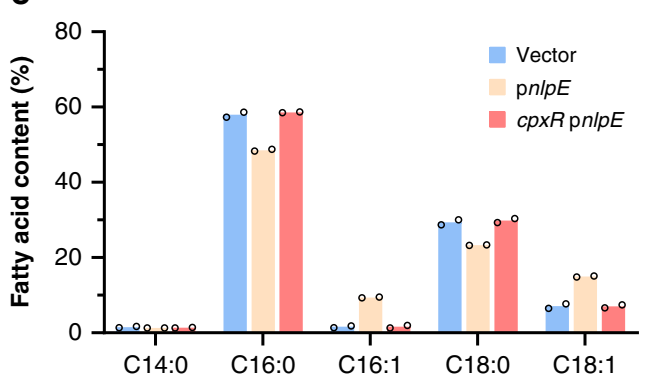

d

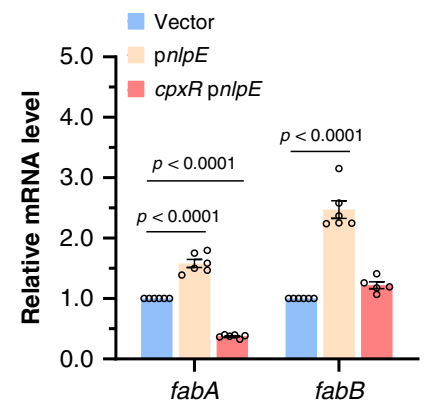

f

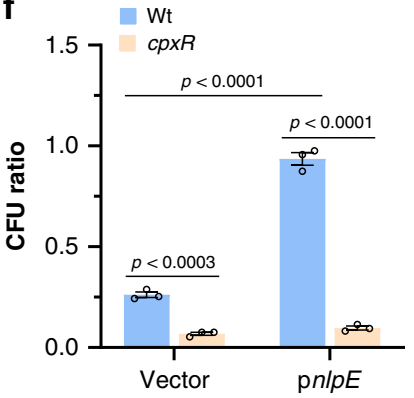

Fig. 2 Transcription of fabA and fabB is activated by two-component system CpxRA. a Schematic diagram showing the genomic locations of fabA and $f a b B$ genes and corresponding CpxR boxes. CB CpxR box. Arrows show the transcription direction of fabA and fabB genes. $\mathbf{b}$ Alignment of $C p x R$ binding sequence and the promoter sequences of fabA and fabB genes. The conserved $\mathrm{CpxR}$ binding sequence was highlighted in red. $\mathbf{c}$ Western blot analysis of $\mathrm{FabA}_{-\mathrm{His}}$ and FabB-His 6 protein in BW25113 strains carrying empty vector or pnlpE, and cpxR mutant carrying pnlpE grown at pH 7.0. Overexpression of outer membrane protein NIpE was reported as a specific activating signal of CpxRA system. The relative amount of each protein was determined using ImageJ from two independent experiments. d Relative mRNA level of fabA and fabB in BW25113 strains carrying empty vector or pnlpE, and $c p x R$ mutant carrying pnlpE grown at $\mathrm{pH} 7.0$ determined by qRT-PCR ( $n=2$ biologically independent samples with three technical repeats). e Membrane lipid composition of BW25113 strains carrying empty vector or pnlpE, and $c p x R$ mutant carrying pnlpE grown at pH 7.0 ( $n=2$ biologically independent samples). The compositions were determined by GC-MS, and fatty acid content is given as the relative peak area [(peak area of one fatty acid/total peak area) $\times$ 100\%]. f Acid tolerance of BW25113 strains carrying empty vector or pnlpE, and $c p x R$ mutant carrying vector or pnlpE after acidic challenge at pH 4.2 for $1 \mathrm{~h}$ ( $n=3$ biologically independent samples). Error bars, mean \pm SEM. Two-tailed Student's $t$ tests were performed to determine the statistical significance for two group comparisons. The source data are provided as a Source Data file.

Transcription start site of $\boldsymbol{f a b}$ genes controlled by CpxRA. We mapped the transcription starts of $f a b A$ and $f a b B$ using RACE (rapid-amplification of cDNA ends) experiment. As was previously reported, for $f a b A$ gene, two transcription initiation sites were detected under growth at $\mathrm{pH}$ 7.0: $\mathrm{S} 1$ positively regulated by $\mathrm{FadR}^{32}$ and $\mathrm{S} 2$ negatively regulated by $\mathrm{FabR}^{33}$. Interestingly, when the cell growth was at $\mathrm{pH} 4.2$, our results indicated that the $f a b A$ gene has a third transcription initiation site located at the 203 bp upstream of the start codon, the S3 (summarized in Fig. 3a). For $f a b B$ gene, the transcription was initiated $37 \mathrm{bp}$ upstream of the start codon in both conditions (summarized in Fig. 3b), consistent with previous reports ${ }^{34}$.
qRT-PCR result showed that the mRNA level of $f a b A$ and $f a b B$ was upregulated by NlpE overexpression in a $f a b R$ fadR double mutant strain, indicating that they had no obvious effect on $f a b A$ and $f a b B$ gene expression under CpxRA-dependent activation (Supplementary Fig. 2).

CpxR protein directly binds to the $f a b A$ and $f a b B$ promoters. To verify the putative CpxR recognition sites, two mutant strains were constructed by site-directed mutagenesis, in which the CpxR binding box on $f a b A$ or $f a b B$ promoter region was replaced by CATCT-(5 nt)-CATCT sequence, and expression of $f a b A$ and $f a b B$ was determined. Both western blot and qRT-PCR results 
a

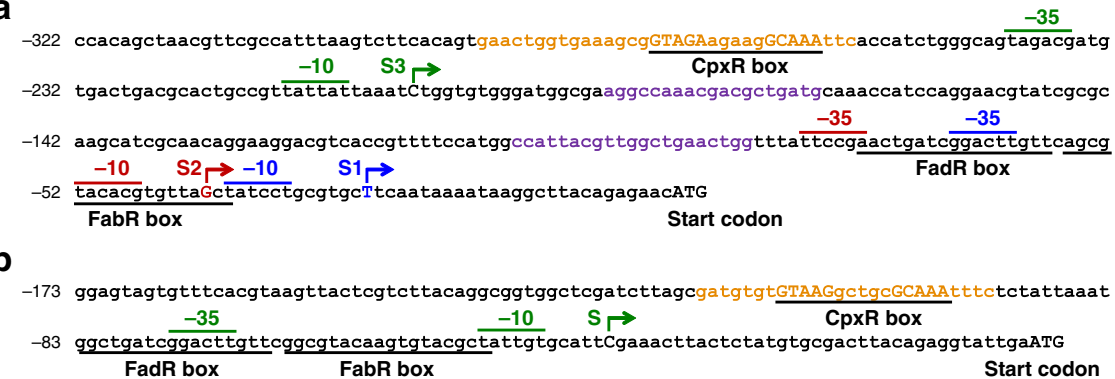

C

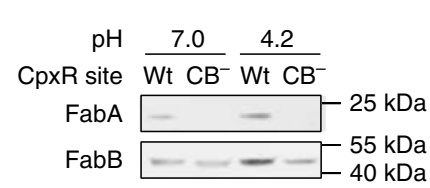

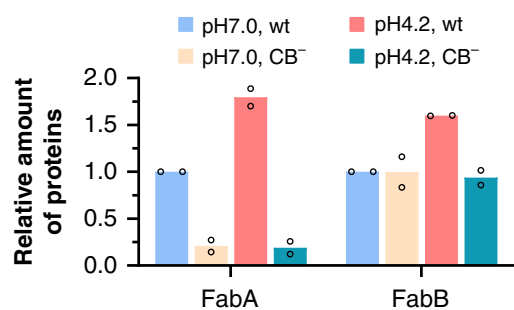

d

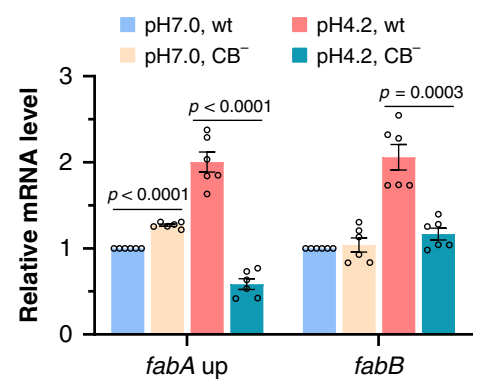

e

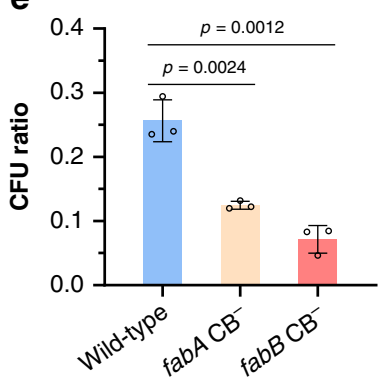

f
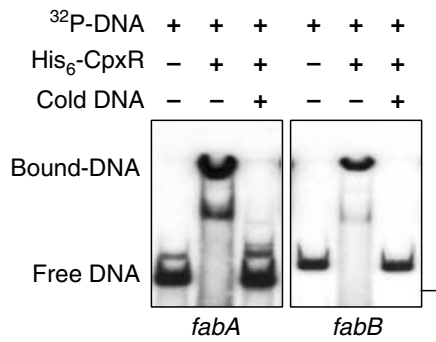

$200 \mathrm{bp}$ g

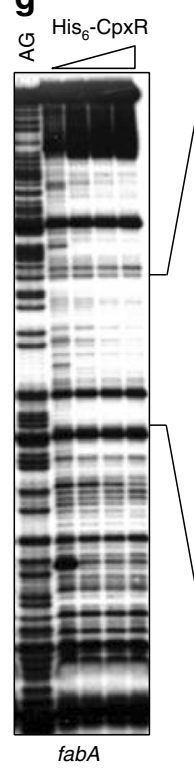

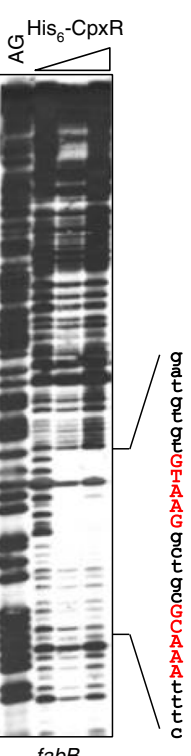

Fig. 3 Identification of CpxR binding sites in the fabA and fabB promoters. a, b DNA sequences of fabA and fabB promoter regions. The FabR box, FadR box and CpxR box sequences were underlined. Two previously reported transcription start sites of fabA, S1 and S2, and corresponding - 35 and -10 regions were shown in blue and red, respectively. The transcription start site identified in this study and its -35 and -10 regions were shown in green. Numbering is from the start codon of each gene. c Western blot analysis of FabA-His 6 and FabB-His 6 in BW25113 wild-type strain at pH 7.0 and 4.2, and strain with $\mathrm{CpxR}$ site substitution at $\mathrm{pH} 7.0$ and 4.2. $n=2$ biologically independent samples. $\mathrm{CB}^{-}$substituted $\mathrm{CpxR}$ box. d Relative mRNA level of fabA and fabB determined by qRTPCR in BW25113 wild-type strain at pH 7.0 and 4.2, and strain with CpxR site substitution at pH 7.0 and 4.2 ( $n=2$ biologically independent samples with three technical repeats). The $f a b A$ up primer sequences were shown in purple in (a). e Acid tolerance of BW25113 wild-type strain and mutants with substitution in fabA or fabB CpxR box after acidic challenge at $\mathrm{pH} 4.2$ for $1 \mathrm{~h}$ ( $n=3$ biologically independent samples). f Gel-shift assay. ${ }^{32} \mathrm{p}$-labeled DNA fragments containing $f a b A$ and $f a b B$ promoter regions were incubated without and with $\mathrm{His}_{6}-\mathrm{CpxR}$ protein, shown in lanes 1-2. Lane 3 is the same as lane 2 but supplemented with "cold" DNA fragments. g DNase I footprinting analysis of fabA and fabB promoters with probes for the noncoding strand and increasing amount of His6-CpxR protein. $\mathrm{His}_{6}-\mathrm{CpxR}$-DNA mixture were subjected to $5 \%$ polyacrylamide electrophoresis, and visualized by autoradiography. The regions protected by $\mathrm{CpxR}$ protein were shown in orange in $(\mathbf{a}, \mathbf{b})$. AG, DNA sequence ladder generated with the same primers using a Maxam and Gilbert $A+G$ reaction. $\mathbf{f}$ and $\mathbf{g}$ are representative results from two independent experiments. Error bars, mean \pm SEM. Two-tailed Student's $t$ tests were performed to determine the statistical significance for two group comparisons. The source data are provided as a Source Data file.

showed that the activating effect of acid stress on expression of $f a b A$ and $f a b B$ was completely eliminated by substitution of CpxR site (Fig. 3c, d). Moreover, the acid tolerance of these mutants significantly decreased (Fig. 3e).

The function of CpxR site was further confirmed in vitro through gel-shift assay and DNase I footprinting analysis using purified $\mathrm{His}_{6}{ }^{-} \mathrm{CpxR}$ protein and 211- and 219-bp DNA fragments corresponding to the promoter regions of $f a b A$ and $f a b B$, respectively. The purified $\mathrm{His}_{6}$-CpxR protein could shift those two DNA fragments (Fig. 3f), and protect the $f a b A$ promoter at the -287 to -255 region (numbering from the start codon) and the $f a b B$ promoter at the -119 to -94 region in the noncoding strand containing the putative CpxR binding site (Fig. 3g). All these results demonstrate that the CpxR protein enhances transcription of $f a b A$ and $f a b B$ by direct binding to their promoters.
CpxRA is directly activated by acidic environments. As a sensor histidine kinase in two-component system, CpxA spans the cell membrane and exposes its sensor domain into the periplasm. When CpxA detects a specific signal, it autophosphorylates and then transports the phosphate group to its cognate regulator CpxR, enabling the regulatory activity of CpxR. Without inducing signal, CpxA acts as a phosphatase to maintain CpxR in an inactive state ${ }^{35,36}$.

To monitor the expression and phosphorylation level of CpxA protein, we constructed a strain carrying chromosomal $\mathrm{His}_{6}{ }^{-}$ tagged CpxA. As shown in Fig. 4a, acid shock significantly enhanced the amount of $\mathrm{CpxA}^{-\mathrm{His}_{6}}$ protein in exponentially growing cells. More importantly, increased level of phosphorCpxA, the active form of CpxA, was detected at pH 4.2 (Fig. 4a).

To demonstrate direct activation of CpxRA upon exposure to acidic $\mathrm{pH}$, we used a reconstituted proteoliposome system, 
a
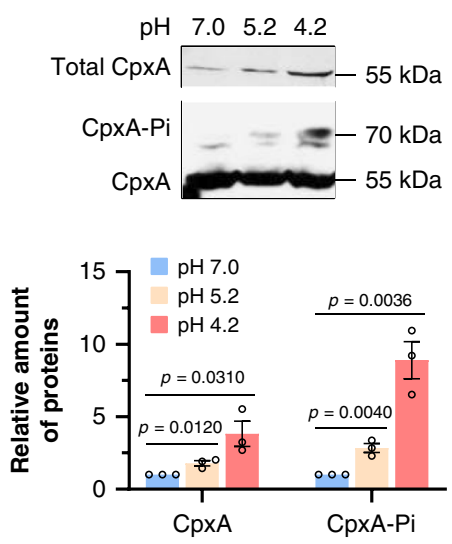

d

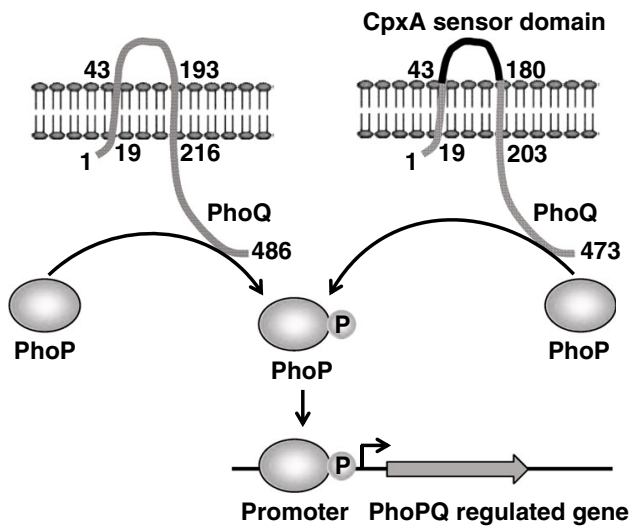

f
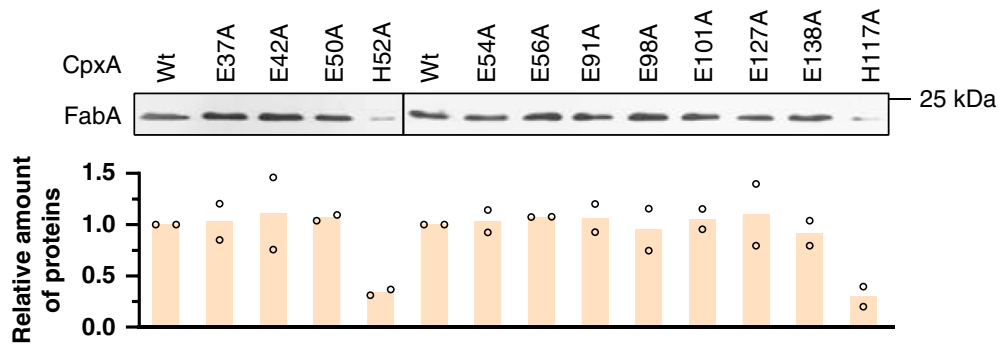

b

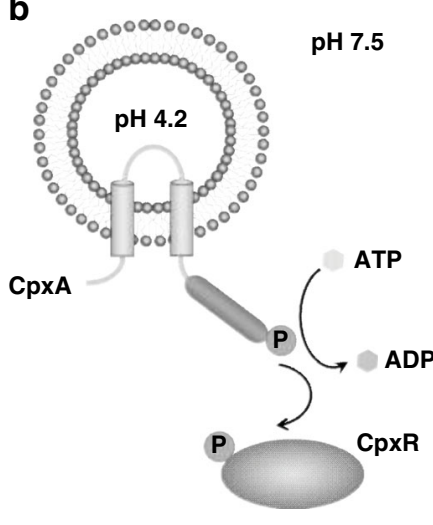

e
C
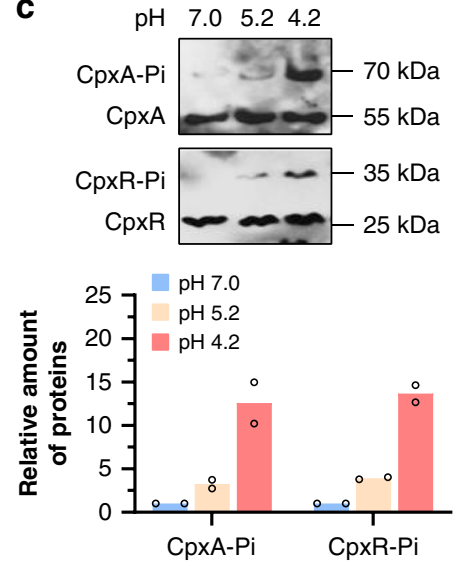
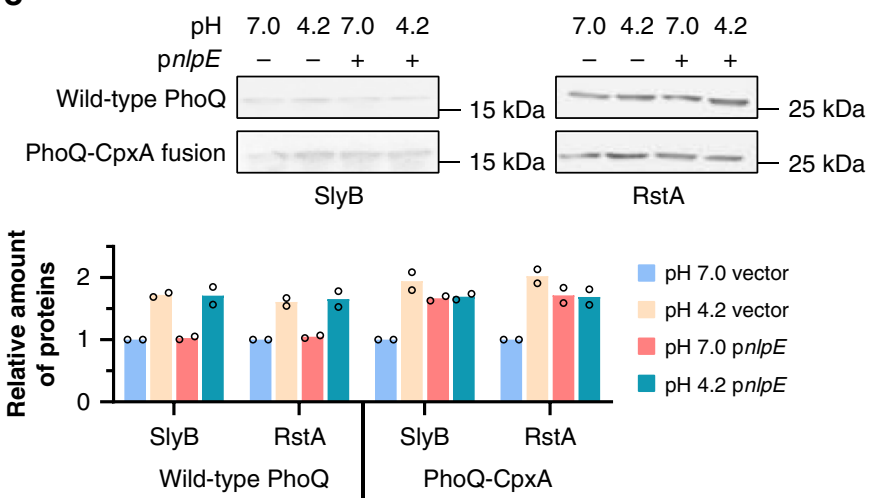

g $\mathrm{pH} 7.0 \quad 4.2$

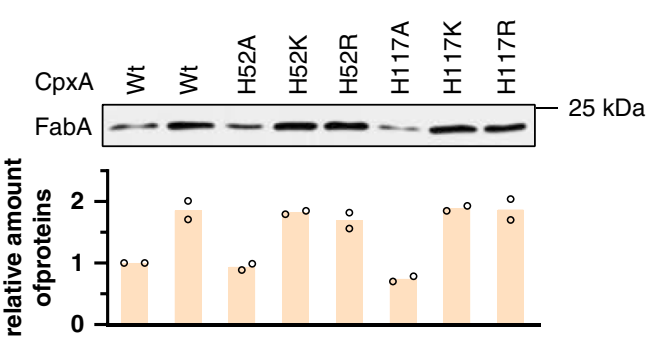

Fig. 4 The CpxRA system is activated by protonation of CpxA periplasmic histidine residues. a Western blot of CpxA-His 6 protein in BW25113 strain after acidic challenge. For total $\mathrm{CpxA}$ protein, the same amount of total cellular proteins extracted from cells grown at different $\mathrm{pH}$ was applied to SDSPAGE. For analysis of phosphorylated CpxA protein, the same amount of $\mathrm{CpxA}-\mathrm{His}_{6}$ protein purified from cells grown at different pH was separated using SDS-PAGE containing $\mathrm{Mn}^{2+}$ and Phos-tag acrylamide, which retard the mobility of phosphoproteins. $n=3$ biologically independent samples. $\mathbf{b}$ Schematic diagram of the proteoliposome system. $\mathbf{c}$ In vitro analysis of $\mathrm{CpxA}$ and $\mathrm{CpxR}$ phosphorylation induced by acidic $\mathrm{pH}$, carried out using reconstituted proteoliposomes, which were preloaded with buffers at different $\mathrm{pH}$ and purified $\mathrm{CpxA}_{\mathrm{H}} \mathrm{His}_{6}$ protein. To analyze phosphotransfer, purified $\mathrm{His}_{6}-\mathrm{CpxR}$ was incubated with $\mathrm{CpxA}_{\mathrm{A}} \mathrm{His}_{6}$-containing proteoliposome in phosphorylation buffer. $n=2$ biologically independent samples. $\mathbf{d}$ Design and construction of a PhoQ-CpxA fusion protein. PhoPQ is a known two-component system which can sense the acidic $\mathrm{pH}$, and activate transcription of $r s t A$ and slyB genes. We replaced the sensor domain of PhoQ (amino acids 43-193) with the periplasmic domain of CpxA (amino acids 28-164). e Western blot of RstA and SlyB proteins in BW25113 with wild-type PhoQ or PhoQ-CpxA fusion at pH 7.0, at pH 4.2, with NlpE overexpression, and at pH 4.2 with NIpE overexpression. $n=2$ biologically independent samples. $\mathbf{f}$ Western blot of FabA-His 6 protein in BW25113 strains carrying wild-type CpxA or CpxA mutants in which the periplasmic histidine/glutamate was replaced with alanine at $\mathrm{pH}$ 4.2. $n=2$ biologically independent samples. $\mathbf{g}$ Western blot of FabA-His ${ }_{6}$ protein in BW25113 strains carrying wild-type CpxA or CpxA mutants in which the histidine at positions 52 and 117 was replaced by alanine, lysine, and arginine, respectively. $n=2$ biologically independent samples. Error bars, mean \pm SEM. Two-tailed Student's $t$ tests were performed to determine the statistical significance for two group comparisons. The source data are provided as a Source Data file.

where a different internal and external $\mathrm{pH}$ can be stably maintained (Fig. 4b). The CpxA-His 6 protein was purified from membranes and reconstituted into vesicles mainly in the insideout orientation using the detergent-mediated method as described ${ }^{37}$. As shown in Fig. $4 \mathrm{c}$, lowering the $\mathrm{pH}$ inside vesicles from 7.0 to 4.2 greatly enhanced the amount of phospho-CpxA. The phosphoryl group was transferred to regulator $\mathrm{CpxR}$ when the $\mathrm{pH}$ inside vesicles was 4.2 , while phosphorylated CpxR could be hardly detected with neutral lumen $\mathrm{pH}$ (Fig. 4c) or without the sensor kinase CpxA. These 
results suggested that $\mathrm{CpxA}$ is capable of activating $\mathrm{CpxR}$ upon direct exposure to acidic environments.

To further verify the sensitivity of CpxA periplasmic domain to acidification, a chromosomal PhoQ-CpxA fusion strain was constructed, in which the sensor domain of PhoQ (amino acids 43-193) was replaced by the periplasmic domain of CpxA (amino acids 28-164) (Fig. 4d). PhoPQ is a known two-component system that can sense the acidic $\mathrm{pH}, \mathrm{Mg}^{2+}$ depletion and antimicrobial peptides, and activate transcription of genes including $r s t A$ and $s l y B^{38,39}$. Western blot results showed that both low $\mathrm{pH}$ and overexpression of NlpE promoted expression of RstA and SlyB in strain carrying the PhoQ-CpxA fusion protein, while only acidic environments increased the protein level of RstA and SlyB in wild-type strain (Fig. 4e). On the other hand, when the CpxA periplasmic domain was replaced with that from another kinase AtoS which senses the presence of acetoacetate ${ }^{40}$, neither could the protein level of $\mathrm{FabA}^{-\mathrm{His}_{6}}$ and FabB-His 6 be enhanced by acidic conditions in vivo, nor could the CpxR protein be phosphorylated at $\mathrm{pH} 4.2$ in reconstituted proteoliposome (Supplementary Fig. 3), indicating that CpxA periplasmic domain is sensitive to acidification. All these results collectively demonstrated that CpxRA system is activated by direct exposure of CpxA periplasmic domain to acidic environments.

CpxA H52 and $\mathrm{H} 117$ are required for sensing of acidic $\mathrm{pH}$. As reported, the histidine and glutamic acid residues were regarded as sensors detecting mild acidic $\mathrm{pH}$ because they can change their protonation state upon variation in the surrounding $\mathrm{pH}^{3,41-43}$. So, we hypothesized that the histidine and glutamate residues in CpxA sensor domain might be required for $\mathrm{pH}$ sensing. To test this hypothesis, we constructed a series of plasmids encoding CpxA mutants in which the periplasmic histidine/glutamate residue was replaced with alanine, respectively. Strains expressing the mutant CpxA proteins could express $f a b A$ in response to NlpE overexpression normally (Supplementary Fig. 4), indicating that mutations in residues of the periplasmic domain of CpxA protein do not impair the kinase activity of CpxA cytoplasmic domain. As shown in Fig. 4f, only two mutants (H52A and H117A) resulted in the loss of CpxA capability to upregulate $f a b A$ expression at $\mathrm{pH} 4.2$, while the other mutations in glutamate residues did not change the expression level of $f a b A$. To confirm that protonation of $\mathrm{H} 52$ and $\mathrm{H} 117$ is responsible for $\mathrm{pH}-$ mediated gene regulation, we also mutated these two residues to other basic amino acids, lysine and arginine, respectively. It was discovered that the substitution of $\mathrm{H} 52$ and $\mathrm{H} 117$ by lysine and arginine had no effect on the response to acidic pH (Fig. $4 \mathrm{~g}$ ). Moreover, the strain carrying CpxA variant with a basic amino acid residue at positions 52 or 117 presented a higher level of FabA protein even at $\mathrm{pH} 7.0$, when compared with strain with CpxA H52A or H117A mutant (Supplementary Fig. 5), probably due to the protonation of basic amino acid residue at $\mathrm{pH}$ 7.0. These results demonstrate that protonation of residues at positions 52 and 117 is required to maintain the response of CpxA to acidic $\mathrm{pH}$, but the presence of a histidine at those positions is not a specific requirement for activation.

Physiological effects of changes in lipid composition. To learn how changed content in membrane lipid affect $E$. coli cell functions and physiology, several assays were carried out using cells carrying empty vector as control, p $f a b A$, or $\mathrm{p} f a b B$, after acidic challenge at $\mathrm{pH}$ 4.2. The membrane fluidity was determined by analyzing the fluorescence anisotropy of 1,6-diphenyl-1,3,5-hexatriene (DPH), which is negatively correlated to fluidity ${ }^{44}$. As shown in Fig. 5 a, the strains with overexpression of $f a b A$ or $f a b B$ presented much less cell membrane fluidity than strain carrying empty vector. The membrane permeability was measured by detecting the leakage of $\mathrm{OD}_{260}$ materials (predominantly nucleotides), and there was no significant difference observed despite the varied UFA contents in membrane (Supplementary Fig. 6). $\mathrm{F}_{0} \mathrm{~F}_{1}$-ATPase spans the cell membrane and transports periplasmic protons to cytoplasm with production of ATP, and lipids are required for its optimal functioning ${ }^{45}$. The activity of $\mathrm{F}_{0} \mathrm{~F}_{1}$-ATPase was measured, and results suggested that the enhancement of UFAs content repressed its activity (Fig. 5b). Then the intracellular $\mathrm{pH}$ was monitored using ratiometric $\mathrm{pH}-$ sensitive GFP pHluorin2 ${ }^{46}$. When growing under $\mathrm{pH}$ 5.0-9.0, E. coli can maintain the intracellular $\mathrm{pH}$ between $\mathrm{pH} 7.4$ and $7.9^{47,48}$. Upon exposure to $\mathrm{pH} 4.2$, the internal $\mathrm{pH}$ of control strain decreased to $6.82 \pm 0.06$, and the homeostasis of $\mathrm{pH}$ in $E$. coli cells with overexpression of $f a b A$ or $f a b B$ was good (Fig. 5c), probably due to the lowered membrane fluidity and $\mathrm{F}_{0} \mathrm{~F}_{1}$-ATPase activity.

As E. coli has to combat a moderate acidic environment ( $\mathrm{pH} 4.0-6.0)$ and proliferate in host's small intestine, we carried out mouse gastrointestinal passage experiment to test the in vivo effect of the UFAs-CpxRA system. BALB/c mice were administered BW25113 wild-type strain or mutant with substituted fabA CpxR binding site, and three independent trials with six mice in each trial were performed for each strain. After $24 \mathrm{~h}$, fecal samples were collected to test the presence of each strain. Out of 18 inoculated mice, the wild-type BW25113 strain was recovered from a total of 8 mice, while the fabA CpxR box mutant was detected in only 2 fecal samples (Fig. 5d). The results between the parental and mutant strains were statistically different $(p<0.05)$, demonstrating that this ATR system significantly promotes E. coli survival in mouse intestinal lumens.

In bio-production of organic acids, product accumulation acidifies the fermentation broth and inhibits the growth of producing strain. Previously, we had constructed a 3-hydroxypropionate (3HP)producing E. coli recombinant strain. In shaking flask cultivation, the $\mathrm{pH}$ of culture decreased to $\mathrm{pH} 5.2-5.5$ along with the production of $3 \mathrm{HP}$, repressing the further production and cell growth (Fig. 5e). So, the $\mathrm{pH}$ of fermentation broth had to be adjusted to 7.0 periodically. Then $f a b A$ gene was overexpressed to enhance E. coli tolerance to acidic environments, leading to similar $3 \mathrm{HP}$ production and cell growth with and without $\mathrm{pH}$ adjustment (Fig. 5e). This result demonstrates the great prospect of UFAs-CpxRA-dependent ATR system in organic acids bio-production.

The UFAs-CpxRA system functions in diverse bacteria species. Salmonella Typhimurium LT2 and Shigella flexneri 2a str. 2457T are both common enteric pathogens, and their FabA proteins share more than $98 \%$ identity with E. coli FabA (Supplementary Fig. 7). To test whether UFAs are required for growth under acidic $\mathrm{pH}$ in these bacteria, the empty vector and recombinant plasmid carrying E. coli fabA gene were transformed into Salmonella Typhimurium LT2 and S. flexneri 2a str. 2457T. In acidic challenge tested at $\mathrm{pH} 5.0$, the transformation of empty vector did not affect the acid tolerance of those two strains, but the overexpression of $f a b A$ gene elevated those CFU ratios by 2.32- and 1.99-fold, respectively (Fig. 6a). Moreover, mRNA level of $f a b A$ and $f a b B$ was upregulated by acid challenge in Salmonella, Klebsiella and Pseudomonas strains (Fig. 6b), and the consensus sequence of CpxR site was also found upstream of the $f a b A$ and $f a b B$ genes in additional bacteria species (Table 1). Additionally, Cronobacter sakazakii clone carrying transposon insertion in $c p x R$ gene was identified as acid-sensitive mutant ${ }^{49}$. All these facts suggest this ATR system functioning in exponential phase is highly conserved across bacteria species. 
a
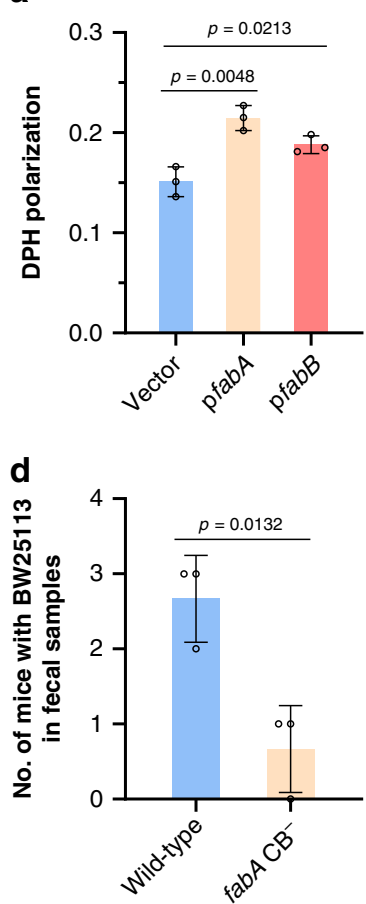

b

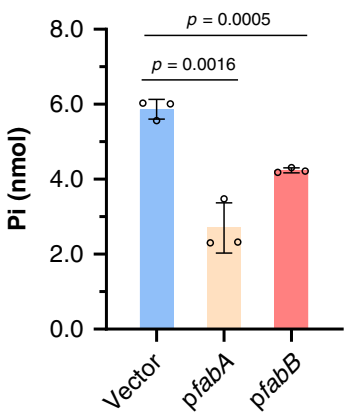

C

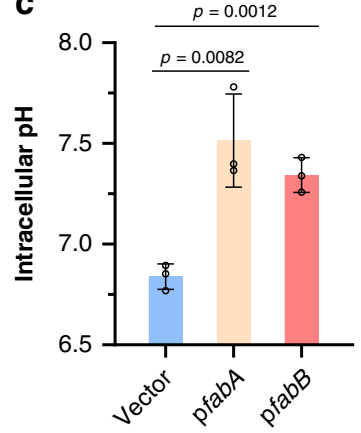

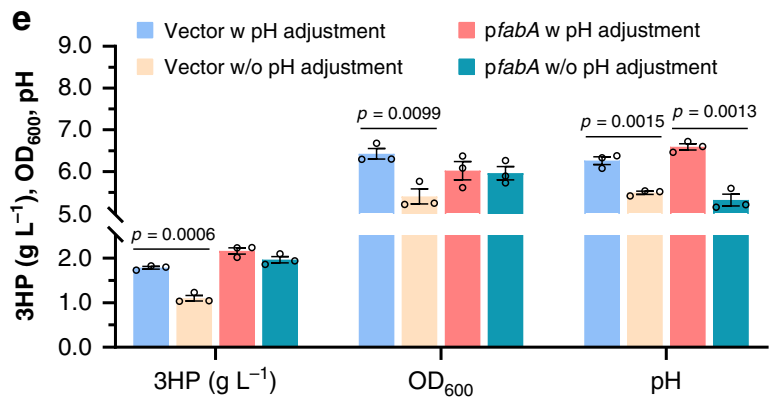

Fig. 5 The UFAs content affects membrane properties, E. coli survival in host's intestine and production of organic acid. The membrane fluidity (a), $\mathrm{F}_{0} \mathrm{~F}_{1}$-ATPase activity (b), and intracellular pH (c) of BW25113 strains carrying empty vector pTrcHis2B, pfabA or pfabB, after acidic challenge at pH 4.2 for $1 \mathrm{~h}$. The membrane fluidity is determined by the anisotropy of fluorescent probe 1,6-diphenyl-1,3,5-hexatriene (DPH). $\mathrm{F}_{0} \mathrm{~F}_{1}-\mathrm{ATPase}$ activity is assayed in terms of the release of inorganic phosphate using permeabilized cells in ATP-containing buffer. The intracellular $\mathrm{pH}$ was monitored using ratiometric $\mathrm{pH}$ sensitive GFP pHluorin2. d Recovery of E. coli BW25113 wild-type strain and mutant with substitution in fabA CpxR site from feces following oral administration to BALB/c mice. Three independent trials with six mice in each trail were performed for each strain. e 3-Hydroxypropionate production, $\mathrm{OD}_{600}$, and final $\mathrm{pH}$ of fermentation broth of recombinant strains with and without fabA overexpression. For experiments with $\mathrm{pH}$ adjustment, the medium was adjusted to $\mathrm{pH} 7.0$ every $12 \mathrm{~h}$. Data are presented as mean \pm SEM of three independent experiments. Two-tailed Student's $t$ tests were performed to determine the statistical significance for two group comparisons. The source data are provided as a Source Data file.
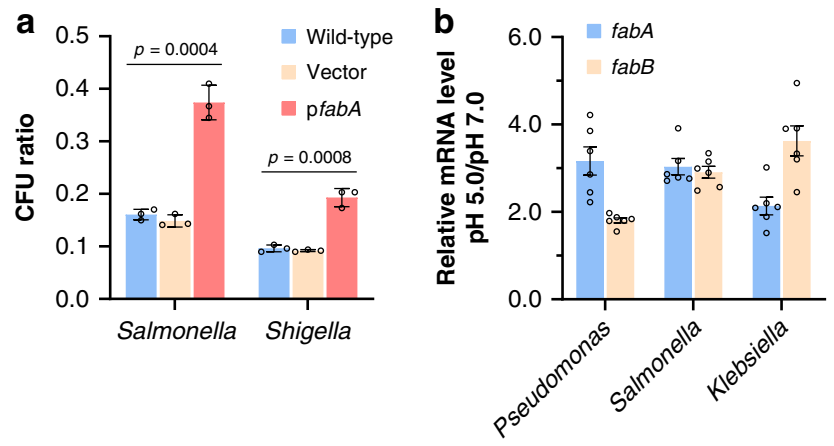

Fig. 6 The exponential phase ATR system based on UFAs and CpxRA is conserved in bacteria. a Acid tolerance of Salmonella Typhimurium LT2 and Shigella flexneri $2 a$ str. $2457 \mathrm{~T}$ wild-type strain and strains carrying empty vector or pfabA after acidic challenge at $\mathrm{pH} 5.0$ for $1 \mathrm{~h}(n=3$ biologically independent samples). b Relative mRNA level of $f a b A$ and $f a b B$ in Salmonella Typhimurium LT2, Klebsiella pneumoniae ATCC25955 and Pseudomonas aeruginosa PAO1 grown at $\mathrm{pH} 7.0$ and $\mathrm{pH} 5.0(n=2$ biologically independent samples with three technical repeats). Error bars, mean \pm SEM. Two-tailed Student's $t$ tests were performed to determine the statistical significance for two group comparisons. The source data are provided as a Source Data file.

\section{Discussion}

According to the results shown above, we present a previously uncharacterized ATR system as well as its regulatory pathway in exponentially growing $E$. coli. We demonstrated that the two-component system CpxRA can directly sense the acidic environments, and activate transcription of UFAs synthetic genes, resulting in increased UFAs contents in cell membrane lipid and normal growth of E. coli at $\mathrm{pH}$ 4.2. Our findings greatly enriched our understanding of the networks contributing to bacterial acid resistance, and the mechanisms for stress response governed by the CpxRA system.

As reported, the acid limit for E. coli growth is $\mathrm{pH} 4.0-4.5$, and all known AR and ATR systems only prolong survival of E. coli cells under acidic conditions, but cannot support growth at $\mathrm{pH}$ $4.0-4.5^{18,21,22}$. In our study, overexpression of $f a b A$ and $f a b B$ genes for UFAs biosynthesis, or activation of the two-component regulatory system CpxRA both restore the growth capability of E. coli at $\mathrm{pH}$ 4.2. Compared with those previously known AR systems, this growth-conferring ATR system is expected to have more important physiological significance. Firstly, bacteria can grow normally under acidic $\mathrm{pH}$ with activation of the CpxRA- and UFAs-dependent system, achieving higher biomass, which may be required for successful pathogenesis and efficient bio-production. Secondly, de novo mutations during DNA duplication play a critical role in bacterial stress resistance development ${ }^{50}$, and the rapid proliferation at low $\mathrm{pH}$ provides an opportunity for the evolution of novel AR and ATR systems. Thirdly, functioning of previously known AR systems is subject to more external limitations, such as AR1 is repressed by glucose and AR2-AR5 are dependent on exogenous amino acids, whereas the UFAs-CpxRA system can be activated by acidic $\mathrm{pH}$ alone because CpxA is capable of phosphorylating CpxR upon exposure to $\mathrm{pH} 4.2$ in a reconstituted proteoliposome system. 


\section{Table 1 Putative CpxR box of fabA and fabB genes from $\mathrm{Gram}^{-}$bacteria (The genome sequences of various bacteria used in this table are under the accession numbers CP009273, NC_003197, NC_002516, NC_011283, NC_013716, CP001235, NC_004741, CP001589, and NC_009778, respectively).}

\begin{tabular}{l} 
Bacteria species \\
\hline E. coli BW25113 \\
Salmonella typhimurium LT2 \\
Pseudomonas aeruginosa PAO1 \\
Klebsiella pneumoniae 342 \\
Citrobacter rodentium ICC168 \\
Vibrio cholerae O395 \\
Shigella flexneri 2a str. 2457 T \\
Yersinia pestis D182038 \\
Cronobacter sakazakii ATCC BAA-894
\end{tabular}

fabA gene

Sequence $^{a}$

GTAGAagaagGCAAA (8)

GTAAAcagggcGTGAT (8)

GGAATtgcaacGCATA (6)

GTAAAcagggcGTCAT (8)

GTAAGcaagggGTAAT (8)

ATAAAtcagtaGTAGA (8)

GTAGAagaagGCAAA (8)

GTACAgaaagGTCAA (8)

GCAAAcagggcGTGAT (8)
fabB gene

\begin{tabular}{ll}
\hline Sequence $^{\mathbf{a}}$ & Position $^{\mathbf{b}}$ \\
\hline GTAAGgctgcGCAAA (8) & -112 to -98 \\
GCAAAtttccGTACT (8) & -103 to -89 \\
GTCGAtggccGCGAA (6) & -83 to -69 \\
GCAAAtttatACACA (6) & -102 to -88 \\
GCAAAtttcgGCAGA (7) & -102 to -88 \\
GAAATcaggctGAATA (6) & -110 to -95 \\
GTAAGgctgcGCAAA (8) & -112 to -98 \\
GTAAAattagtGGAAG (8) & -25 to -10 \\
GCAAAtttcttGCCAA (7) & -101 to -86
\end{tabular}

aNumber of bases same with the $\mathrm{CpxR}$ site consensus was presented in the parenthesis.

bNumbering is from the start codon of fabA or fabB gene.

We proved that the transcription of $f a b A$ stimulated by CpxRA is required for multiplication of $E$. coli in mouse intestine, indicating that UFAs-CpxRA system is also related to pathogenesis of E. coli pathovars, as well as those previously known AR systems. While various pathotypes of $E$. coli colonize and infect different organs, they all have to combat acidic environments during invading the host's digestive tract. With $\mathrm{pH}$ values as low as $1.5-2.5$, the stomach has been recognized as a natural antibiotic barrier ${ }^{1}$. Benefited from AR1-AR5 systems, E. coli can survive in the gastric acid for hours ${ }^{22,51}$. With their passage into the small intestine, $E$. coli cells will encounter a less acidic environment $(\mathrm{pH}$ 4.0-6.0) with the presence of organic acids produced by the normal intestinal flora ${ }^{2}$. As pathogenic $E$. coli strains must reproduce rapidly to cause disease ultimately ${ }^{52}$, the UFAs-CpxRA system is likely to play a key role. In summary, the successful enteric pathogen must possess two abilities, survival in extreme acidic condition and quick growth in moderate acidic environment. Consequently, this ATR system may be a new target for the development of antimicrobials.

UFAs-CpxRA-dependent ATR system also has potential application in bio-production of organic acids, which are valuable platform chemicals and have been successfully produced by recombinant E. coli strains ${ }^{53,54}$. However organic acids cause acidification of fermentation broth and inhibit E. coli growth at concentrations far below what is required for economical production. Now large quantity of base titrant are required to raise $\mathrm{pH}$ of the media in organic acids production process, and large amounts of acid must be consumed to recover the organic acids in the protonated form after production. If we could construct acid-tolerant strains growing at a $\mathrm{pH}$ less than the $\mathrm{pKa}$ of the produced acid, the additional consumption of acid and base titrants will be circumvented and the overall production cost will be lowered remarkably. As the UFAs-CpxRA system functions in exponential phase, is not repressed by glucose (the carbon source in most fermentation), and does not need exogenous amino acids, it is believed that this ATR system could be effectively applied in the field of organic acids bio-production.

Our data suggested that UFAs played an important role in protection of exponential phase E. coli from acid shock. The increase of UFAs content in membrane lipid not only affected the fluidity of lipid bilayer but also changed the activity of the $\mathrm{F}_{0} \mathrm{~F}_{1}$-ATPase, conducing to reduced membrane proton permeability and improved internal $\mathrm{pH}$ homeostasis. This phenomenon is consistent with that $S$. mutants cells grown at $\mathrm{pH} 5.0$ had higher UFAs composition and lower proton permeability than those grown at $\mathrm{pH} 7.0^{27,55}$. Moreover, changes in fatty acid composition probably also affect the PTS system and enzyme secretion 56,57 . Overall, changing membrane fatty acid composition may improve the bacterial ability to adapt to acidic environment and be an important factor in bacterial acid response. In this study, the cyclopropane fatty acid (CFA) could not be detected in exponential phase E. coli cells, although it was regarded as a major factor in acid resistance of stationary phase $E$. coli $^{24,58}$. However, UFA can be converted into CFA by CFA synthase $^{59}$, and increased UFAs content will potentially enable the synthesis of CFA in stationary phase.

We demonstrate that the E. coli kinase CpxA is a direct sensor for acidic $\mathrm{pH}$. Our data provide strong evidence that a decrease in $\mathrm{pH}$ protonates the histidine residues at positions 52 and 117 in CpxA periplasmic domain, leads to events catalyzed by its cytoplasmic domain, including phosphorylation of CpxA, transfer of phosphoryl group to regulator CpxR, as well as activation of CpxR-dependent gene transcription. As titratable by $\mathrm{pH}$, histidine has been regarded as sensor detecting mild acidic $\mathrm{pH}$, and also plays an essential role in the activation of sensor kinase PhoQ by acidic $\mathrm{pH}^{60}$. But the molecular details of how histidine senses the low $\mathrm{pH}$ signal in PhoQ and CpxA are different. Protonation of residues at positions 52 and 117 is effective to activate CpxA at acidic $\mathrm{pH}$, whereas the imidazole ring of histidine is important in maintaining the response of PhoQ to acidity ${ }^{60}$.

Our results evidenced that CpxRA is a key system in the acid stress response of exponentially growing E. coli (Fig. 7), consistent with a previous proteomic analysis highlighting the importance of CpxRA in acid stress ${ }^{61}$. Upon exposure to acidic environments, CpxRA system stimulates the transcription of UFAs synthetic genes, resulting in improved intracellular $\mathrm{pH}$ homeostasis. Additionally, CpxRA upregulates some genes involved in cell wall modification, including peptidoglycan (PG) cross-linking proteins YcfS, YcbB and DacC; PG cleaving proteins AmiA, AmiC and $\mathrm{Slt}^{61-63}$. The induction of those genes led to an increase of crosslinking between PG and outer membrane proteins, and an increase of cell wall stability, which may help protecting $E$. coli cells from acidic challenge. That proteomic study also indicated the repression of AR2 system by CpxRA ${ }^{61}$. Because AR2 system is responsible for survival below pH 3.0 and log phase cells with overexpression of AR2 genes are not more acid resistant ${ }^{4}$, the CpxRA-mediated repression of AR2 in exponentially growing cells above $\mathrm{pH} 3.0$ will guarantee that AR2 system is not induced in an inappropriate situation to avoid the metabolic burden. Furthermore, the sensor kinase CpxA was proved to cross-talk with noncognate response regulator $\mathrm{OmpR}^{64}$, which itself is involved in the acid stress response of E. coli ${ }^{65,66}$. All of these data indicate that $E$. coli has 


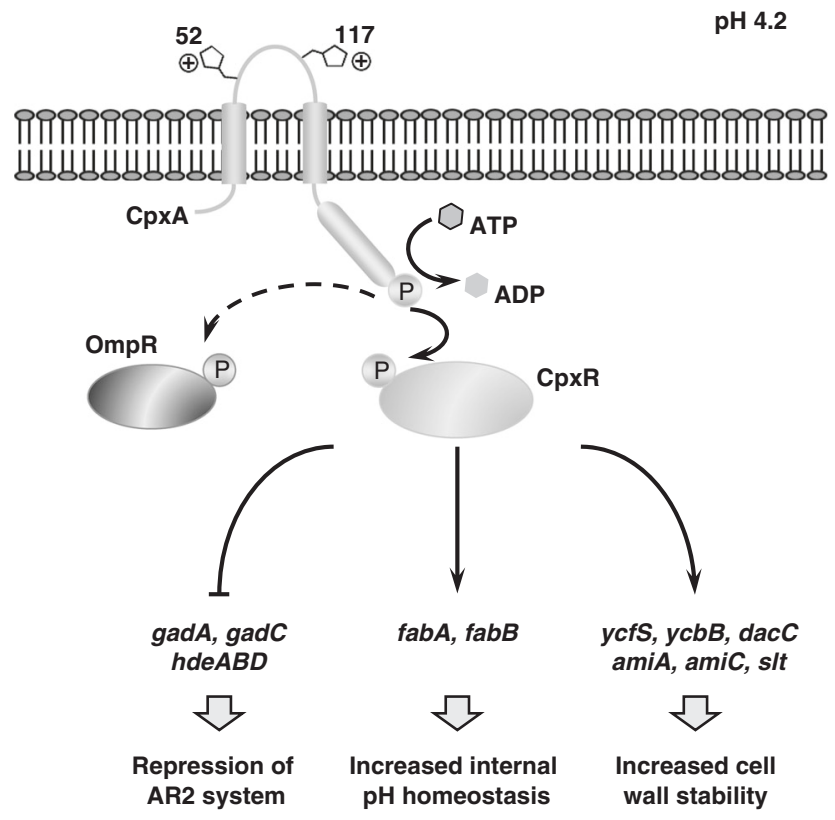

Fig. 7 Model illustrating the CpxRA-dependent gene regulation involved in exponential phase ATR system. In exponentially growing E. coli, CpxRA system is activated by moderate acidic $\mathrm{pH}$ through protonation of periplasmic histidine residues, and upregulates the transcription of UFAs biosynthesis genes $f a b A$ and $f a b B$, and cell wall modification genes including $y c f S, y c b B, d a c C, s / t, a m i A$ and $a m i C$, and represses the expression of AR2 system genes. The sensor kinase $\mathrm{CpxA}$ also interacts with noncognate response regulator $\mathrm{OmpR}$, which itself plays an important role in $E$. coli acid resistance.

evolved multiple acid response mechanisms as well as precise regulatory circuits, to target specific stress conditions.

In many Gram-negative pathogens, the CpxRA system plays an important role in the regulation of virulence factors, including pilus, secreted virulence effectors and type III secretion system ${ }^{36}$. For CpxRA to upregulate expression of these virulence genes, there must be an activating signal for CpxA under in vivo conditions. The identity of this signal still remains a topic of much debate. According to the results in this study, we propose that moderate acidic $\mathrm{pH}$ (such as the intestine and macrophage) is the activating signal of CpxA in vivo. As the previous study showed that CpxRA also contributed to bacterial resistance to antimicrobial peptides, a component of the host antimicrobial response ${ }^{62}$, acidic $\mathrm{pH}$ and antimicrobial peptide may have synergistic effect on CpxRA activation. Further study is ongoing to address this hypothesis.

\section{Methods}

Bacterial strains and growth conditions. All strains and plasmids used in this study are listed in Supplementary Data 1, and all primers used are listed in Sup plementary Data 2. Phage P1 was used for generalized transductions in E. coli. Bacteria were grown at $37^{\circ} \mathrm{C}$ in Luria-Bertani broth (Oxoid) or in $\mathrm{E}$ minimal medium $\left(0.8 \mathrm{mM} \mathrm{MgSO}, 10 \mathrm{mM}\right.$ citric acid, $57.5 \mathrm{mM} \mathrm{K}_{2} \mathrm{HPO}_{4}, 16.7 \mathrm{mM}$ $\mathrm{NaNH}_{3} \mathrm{HPO}_{4}, 0.5 \%$ glucose). When necessary, antibiotics were added at final concentrations of $100 \mu \mathrm{g} \mathrm{mL}^{-1}$ for ampicillin, $20 \mu \mathrm{g} \mathrm{mL}^{-1}$ for chloramphenicol or $50 \mu \mathrm{g} \mathrm{mL}^{-1}$ for kanamycin. E. coli DH5a was used as host for the preparation of plasmid DNA, and E. coli $\chi 7213$ was used for preparation of suicide vectors. Diaminopimelic acid $\left(50 \mu \mathrm{g} \mathrm{mL}^{-1}\right)$ was used for the growth of $\chi 7213$ strain. LB agar containing $10 \%$ sucrose was used for $s a c B$ gene-based counter selection in allelic exchange experiments. The software ImageJ (version 1.52a) was used to analyze western blot results, and the online version of Clustal Omega (https://www. ebi.ac.uk/Tools/msa/clustalo) was used for sequence alignment.

Plasmids were constructed by digesting PCR fragments containing target gene and cloning into corresponding vectors as normal. Derivatives of pTrc-cpxA with nucleotide substitutions were constructed using Q5 Site-Directed Mutagenesis Kit (New England Biolabs) according to the manufacturer's specifications. All plasmids were confirmed by DNA sequencing. Strains harboring chromosomal epitopetagged proteins were generated using $\lambda$ Red recombinase system ${ }^{67,68}$. DNA fragments encoding PhoQ-CpxA fusion or carrying substituted CpxR site were generated by joint PCR using primers shown in Supplementary Data 2, and cloned into the suicide vector pRE1 $12^{69}$. The resulting plasmids were used to mediate the allelic exchange to generate strains with chromosomal PhoQ-CpxA fusion and CpxR site mutation.

In acidic challenge experiments, the strains were grown in $\mathrm{E}$ medium ( $\mathrm{pH} 7.0)$ to an $\mathrm{OD}_{600}$ of 0.6 . For strains with plasmid, IPTG was added to final concentration of $0.5 \mathrm{mM}$ at an $\mathrm{OD}_{600}$ of 0.4 , and the strain was further grown to an $\mathrm{OD}_{600}$ of 0.6. Then, the cells were harvested and washed twice with fresh E medium ( $\mathrm{pH} 7.0$ ), and inoculated into E medium with various $\mathrm{pH}$ as indicated, and strains were grown for another 30-60 min before the cells were collected to determine the CFU, membrane lipid composition, mRNA and protein levels.

Determination of fatty acid compositions. Phospholipids were extracted as described by Wang and Cronan ${ }^{23}$. Briefly, E. coli cells were harvested and resuspended in $1 \mathrm{~mL}$ sterile water, and $5 \mathrm{~mL}$ of chloroform-methanol $(2: 1 \mathrm{vol} / \mathrm{vol})$ was added and vortexed for $3 \mathrm{~min}$ then stewing overnight. The solution was centrifuged and the upper phase was removed, an equal volume of $2 \mathrm{M} \mathrm{KCl}$ was added, followed by mixing and centrifugation. The top $\mathrm{KCl}$ phase was removed, an equal volume of water was added, followed by mixing and centrifugation. The resulting bottom organic phase was dried under a stream of nitrogen. Two milliliters of methyesterification reagent $\left(\mathrm{BF}_{3}: \mathrm{CH}_{3} \mathrm{OH}=1: 4\right)$ was added and incubated at $60{ }^{\circ} \mathrm{C}$ for $30 \mathrm{~min}$. The resulting solution was extracted with $\mathrm{n}$-hexane for three times and then detected with Agilent GC-MS (7890A-5975C; Column: Agilent-HP-INNOWax). The fatty acids were identified by comparing the retention times and mass fragmentation patterns with authentic standards. Content of each fatty acid is given as the relative peak area [(peak area of one fatty acid/total peak area) $\times 100 \%$ ]

Immunoblot analysis of $\mathbf{H i s}_{\mathbf{6}}$-tagged proteins. The E. coli cells were disrupted by sonication, the cell lysates were centrifuged, and the supernatants were used for western blot. Protein concentration was determined using BCA protein assay kit (Pierce), and the same amount of protein sample was separated in 12\% SDS-PAGE, transferred to nitrocellulose membranes (Bio-Rad), and incubated with monoclonal HRP-conjugated anti-6 $\times$ His antibodies (1:10,000 diluted) (Abcam). Protein signals were detected using Immobilon Western HRP substrate (Millipore) and Xray film. To separate the phosphorylated proteins, 20-50 $\mu \mathrm{M}$ Phos-tag Acrylamide

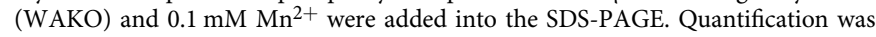
conducted using ImageJ software (NIH).

Quantitative RT-PCR and RACE. Total RNA was isolated from bacterial culture using EASYSpin Plus bacterial RNA quick extract kit (Aidlab Biotechnologies, China) according to the manufacturer's instructions. RNA concentration was determined by spectrophotometry at $260 \mathrm{~nm}$. Removal of genomic DNA and synthesis of cDNA were carried out using PrimeScript RT reagent Kit with gDNA Eraser (Takara). qRT-PCR was conducted using TB Green Premix Ex Taq (Takara) with the QuantStudio 1 system (Applied Biosystems). Constitutively transcribed gene $r p o D$ was used as a reference control to normalize total RNA quantity of different samples. The relative difference of mRNA level was calculated using the $\Delta \Delta \mathrm{Ct}$ method $^{70}$. Two independent biological samples with three technical repeats for each sample were performed for each qRT-PCR analysis.

The RACE experiment was performed using SMARTer RACE cDNA Amplification Kit (Clontech), according to the manufacturer's instructions. The primers $1128+1129$ and $1130+1131$ were used to determine the transcription start sites of $f a b A$ and $f a b B$ under the NlpE overexpression conditions, respectively.

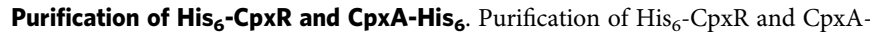
$\mathrm{His}_{6}$ was conducted according to Fleischer et al. ${ }^{37}$. Briefly, E. coli strain BW25113 with pTrc-cpxR or pTrc-cpxA was grown at $37^{\circ} \mathrm{C}$ with aeration in $\mathrm{LB}$ medium. Gene expression was induced with $0.5 \mathrm{mM}$ IPTG for $3-4 \mathrm{~h}$. Membrane fractions and cytosolic fraction were separated by ultracentrifugation ${ }^{37}$. $\mathrm{His}_{6}$-CpxR was solubilized in cytosolic fraction and purified by Ni-affinity chromatography. Membrane proteins were solubilized with $1 \%$ dodecyl- $\beta$-D-maltoside (DM), and then $\mathrm{CpxA}-\mathrm{His}_{6}$ was also purified by $\mathrm{Ni}$-affinity chromatography.

Preparation of proteoliposomes. Proteoliposome was reconstructed as previously described with small modification ${ }^{37}$. Briefly, E. coli phospholipids (Avanti) were dried under a stream of nitrogen, and slowly dissolved in sodium citratehydrochloric acid buffer ( $\mathrm{pH} 7.0,5.0,4.2)$ with $10 \%$ glycerol (vol/vol) and $0.47 \%$ Triton X-100 (vol/vol), respectively. Purified CpxA-His 6 was added to the mixture and stirred at room temperature for $20 \mathrm{~min}$. Bio-Beads SM-2 (Bio-Rad) were added in a bead/detergent ratio of $10: 1(\mathrm{w} / \mathrm{w})$, and the mixture was gently stirred at $4{ }^{\circ} \mathrm{C}$ overnight. After $16 \mathrm{~h}$, fresh Bio-Beads were added, and the mixture was stirred for another $6 \mathrm{~h}$. The proteoliposomes were collected by ultracentrifugation. To test autophosphorylation, proteoliposomes were incubated with $300 \mu \mathrm{mol}$ ATP in phosphorylation buffer ( $50 \mathrm{mM}$ Tris- $\mathrm{HCl}, \mathrm{pH} 7.5,10 \%$ glycerol (vol/vol), $2 \mathrm{mM}$ dithiothreitol (DTT), $50 \mathrm{mM} \mathrm{KCl,} 5 \mathrm{mM} \mathrm{MgCl}_{2}$ ) at room temperature for $30 \mathrm{~min}$. $5 \times$ SDS sample buffer was loaded to termination reaction. To analyze 
phosphortransfer, purified $\mathrm{His}_{6}$-CpxR was added to this mixture and incubated at room temperature for $20 \mathrm{~min}$. Then samples were ultracentrifugated and the upper phase was collected. $5 \times$ SDS sample buffer was loaded to stop the reaction. To detect the phosphorylation level of CpxA and CpxR, all the samples were subjected to $8 \%$ SDS-PAGE with 20-50 $\mu \mathrm{M}$ Phos-tag Acrylamide (WAKO) and $0.1 \mathrm{mM} \mathrm{Mn}^{2+}$ which can retard the mobility of phosphoproteins to show the phosphorylated and nonphosphorylated forms in two separated bands.

Electrophoretic mobility shift assay (EMSA). Primers 683 and 685 were labeled using T4 polynucleotide kinase (New England Biolabs) and $\gamma^{32} \mathrm{P}$ ATP (PerkinElmer Life Sciences). The promoter regions of $f a b A$ and $f a b B$ genes were amplified with primers $682+683$ and $684+685$, respectively. Ten nmol of ${ }^{32} \mathrm{P}$ labeled DNA was incubated at room temperature for $30 \mathrm{~min}$ with 0 or $50 \mathrm{pmol}$ of $\mathrm{His}_{6}-\mathrm{CpxR}$ protein in $20 \mu \mathrm{L}$ of an EMSA buffer consisting of $10 \mathrm{mM}$ Tris- $\mathrm{HCl}, \mathrm{pH}$ 7.5, $1 \mathrm{mM}$ ethylene diamine tetraacetic acid, $5 \mathrm{mM}$ DTT, $10 \mathrm{mM} \mathrm{NaCl}, 1 \mathrm{mM}$ $\mathrm{MgCl}_{2}$, and $5 \%$ glycerol. The mixture was subjected directly to $4 \%$ TAE-PAGE. Signals were detected by autoradiography.

DNase I footprinting assay. DNase I footprinting assays were carried out using the $f a b A$ promoter region amplified from BW25113 chromosome with primers 682 and ${ }^{32} \mathrm{P}-683$ and using the $f a b B$ promoter region amplified with primers 684 and ${ }^{32} \mathrm{P}-685$ for the noncoding strand. Approximately $25 \mathrm{pmol}$ of ${ }^{32} \mathrm{P}$-labeled DNA and $0,25,50$, or $100 \mathrm{pmol}$ of $\mathrm{His}_{6}$-CpxR protein were mixed in a $100-\mu \mathrm{L}$ reaction containing $20 \mathrm{mM}$ 2-[4-(2-hydroxyethyl)piperazin-1-yl] ethanesulfonic acid $\mathrm{pH}$ 8.0, $10 \mathrm{mM} \mathrm{KCl}, 1 \mathrm{mM}$ DTT, and $0.1 \mathrm{mg} \mathrm{mL}^{-1}$ bovine serum albumin. The reaction mixture was incubated at room temperature for $20 \mathrm{~min}$. Then $1 \mu \mathrm{L}$ of $100 \mathrm{mM}$ $\mathrm{CaCl}_{2}, 1 \mu \mathrm{L}$ of $100 \mathrm{mM} \mathrm{MgCl}$, and 0.005 units of DNase I (Fermentas) were added, and the mixture was incubated at room temperature for $2 \mathrm{~min}$. The DNase I digestion was stopped by phenol treatment, and the DNA was precipitated. Samples were analyzed by $6 \%$ polyacrylamide electrophoresis by comparison with a DNA sequence ladder generated with the same primers using a Maxam and Gilbert $\mathrm{A}+\mathrm{G}$ reaction.

Membrane property assays. The membrane fluidity was measured by applying $\mathrm{DPH}$ as a fluorescence probe ${ }^{44}$. Briefly, the washed cells were incubated in DPH (Sigma) at a final concentration of $2 \mu \mathrm{M}$, then shaken in the dark at $30^{\circ} \mathrm{C}$ for $40 \mathrm{~min}$. After incubation, the unincorporated DPH was removed by washing with phosphate-buffered saline (PBS) twice. The cells were resuspended in PBS to get a final density of $\mathrm{OD}_{600}=0.2$ for the measurement of fluorescence anisotropy on a FluoroMax-4 spectrofluorometer (HORIBA Jobin Yvon). The wavelengths were 342 and $432 \mathrm{~nm}$ and slit widths were 5 and $10 \mathrm{~nm}$ for excitation and emission light, respectively. The fluorescence anisotropy, which was negatively correlated with membrane fluidity, was calculated ${ }^{44}$. For the permeability assay, the washed cells were resuspended in PBS for $30 \mathrm{~min}$. The release of nucleotides was then measured at an optical density of $260 \mathrm{~nm}$.

Intracellular pH measurement. The gene encoding ratiometric $\mathrm{pH}$-sensitive green florescent protein pHluorin 2 was synthesized and cloned into vector pBAD-18kan. Excitation assays were performed at wavelengths 395 and $475 \mathrm{~nm}$ with the emission at $510 \mathrm{~nm}$ using FluoroMax-4 Spectrofluorometer (HORIBA Jobin Yvon), and the ratio of fluorescence at 395 to $475 \mathrm{~nm}$ was used to calculate the intracellular $\mathrm{pH}$ according to a standard curve ${ }^{46}$.

$\mathbf{F}_{\mathbf{0}} \mathbf{F}_{\mathbf{1}}$-ATPase activity assay. The cells were washed once and resuspended in 1.8 $\mathrm{mL}$ membrane buffer $\left(75 \mathrm{mM}\right.$ Tris $\mathrm{pH} 7.0,10 \mathrm{mM} \mathrm{MgSO}_{4}$ ). Toluene was added to a final concentration of $10 \%(\mathrm{vol} / \mathrm{vol})$, and the suspension was vortexed for $30 \mathrm{~s}$ and subjected to two rounds of freeze-thawing. Cells were collected, resuspended in membrane buffer. ATPase activity was assayed in terms of the release of inorganic phosphate in $50 \mathrm{mM}$ Tris-maleate buffer $\mathrm{pH} 7.0$, containing $10 \mathrm{mM} \mathrm{MgSO}$ and $50 \mu \mathrm{M}$ ATP. Phosphate was assayed by the malachite green method, using Malachite Green Phosphate Assay Kit (Cayman Chemical).

Mouse survival passage experiments. Female BALB/c mice were housed individually in pathogen-free facility and given food and water ad libitum until 6-weekold. BW25113 strain and mutant with substitution in $f a b A$ CpxR site were grown in $\mathrm{LB}$ at $37^{\circ} \mathrm{C}$ to $\log$ phase, and then $10^{4} \mathrm{CFUs}$ of bacteria were orally administrated to mice. To allow for inoculum clearance through the stomach, the mice were not provided feed for $4 \mathrm{~h}$ after oral administration. Fecal samples were collected $24 \mathrm{~h}$ after inoculation and suspended in PBS $(0.5 \mathrm{~g}$ feces $/ 4.5 \mathrm{~mL}$ PBS $)$ and subsequently diluted. The diluted samples were then plated on LB agar containing nalidixic acid $\left(20 \mu \mathrm{g} \mathrm{mL}^{-1}\right)$ to test for the presence or absence of corresponding strains. Three independent trials were performed for each strain, and in each trial six mice were inoculated. This experiment was performed following the Guide for the Care and Use of Laboratory Animals (National Institutes of Health, 1985).

3-Hydroxypropionate production. The strains were grown overnight in LB broth and 1:100 diluted into $250 \mathrm{~mL}$ Erlenmeyer flasks with $50 \mathrm{~mL}$ of minimal medium containing $14 \mathrm{~g} \mathrm{~L}^{-1} \mathrm{~K}_{2} \mathrm{HPO}_{4} \cdot 3 \mathrm{H}_{2} \mathrm{O}, 5.2 \mathrm{~g} \mathrm{~L}^{-1} \mathrm{KH}_{2} \mathrm{PO}_{4}, 1 \mathrm{~g} \mathrm{~L}^{-1} \mathrm{NaCl}, 1 \mathrm{~g} \mathrm{~L}^{-1}$
$\mathrm{NH}_{4} \mathrm{Cl}, 0.5 \mathrm{~g} \mathrm{~L}^{-1} \mathrm{MgSO}_{4}, 0.2 \mathrm{~g} \mathrm{~L}^{-1}$ yeast extract, and $20 \mathrm{~g} \mathrm{~L}^{-1}$ glucose. All shake flask experiments were carried out in triplicates. After incubation at $37^{\circ} \mathrm{C}$, $0.05 \mathrm{mM}$ IPTG was added for induction at $\mathrm{OD}_{600} 0.8$, and $3 \mathrm{~h}$ later, biotin $\left(40 \mathrm{~m} \mathrm{~L} \mathrm{~L}^{-1}\right)$ and $\mathrm{NaHCO}_{3}(20 \mathrm{mM})$ were added. The antibiotics were supplied periodically after induction of IPTG every $12 \mathrm{~h}$ until $48 \mathrm{~h} .10 \mathrm{~g} \mathrm{~L}^{-1}$ glucose was added once again after $24 \mathrm{~h}$ induction. $3 \mathrm{HP}$ concentration in medium was determined using Agilent 1200 Infinity HPLC system with an Aminex HPX-87H column $(300 \times 7.8 \mathrm{~mm} \text {, Bio-Rad })^{54}$.

Ethics declarations. The animal experiments were performed according to the standards set forth in the Guide for the Care and Use of Laboratory Animals (National Institutes of Health, 1985). Experimental protocols were approved by the Institutional Animal Care Committee at Qingdao Institute of Bioenergy and Bioprocess Technology.

Reporting summary. Further information on research design is available in the Nature Research Reporting Summary linked to this article.

\section{Data availability}

The source data underlying Figs. 1a, b, d-g, 2c-f, $3 c-g, 4 a, c, e-g, 5 a-e$, and $6 a, b$ and Supplementary Figs. 1, 2, 3b, c, 4, 5, and 6 are provided as a Source Data file. The FabA sequences used in this study are under the accession numbers AIN31422, NP_460041, and EFS15200. The genome sequences used in this study are under the accession numbers CP009273, NC_003197, NC_002516, NC_011283, NC_013716, CP001235, NC_004741, CP001589, and NC_009778. Other data supporting the findings of this study are available from the corresponding authors upon request.

Received: 18 June 2019; Accepted: 5 March 2020;

Published online: 20 March 2020

\section{References}

1. Foster, J. W. Escherichia coli acid resistance: tales of an amateur acidophile. Nat. Rev. Microbiol. 2, 898-907 (2004).

2. Lin, J. et al. Mechanisms of acid resistance in enterohemorrhagic Escherichia coli. Appl. Environ. Microbiol. 62, 3094-3100 (1996).

3. Lund, P., Tramonti, A. \& De Biase, D. Coping with low $\mathrm{pH}$ : molecular strategies in neutralophilic bacteria. FEMS Microbiol. Rev. 38, 1091-1125 (2014).

4. Foster, J. W. Acid stress responses of Salmonella and E. coli: survival mechanisms, regulation, and implications for pathogenesis. J. Microbiol. 39, 89-94 (2001).

5. Castanie-Cornet, M. P., Penfound, T. A., Smith, D., Elliott, J. F. \& Foster, J. W Control of acid resistance in Escherichia coli. J. Bacteriol. 181, 3525-3535 (1999).

6. Lin, J., Lee, I. S., Frey, J., Slonczewski, J. L. \& Foster, J. W. Comparative analysis of extreme acid survival in Salmonella typhimurium, Shigella flexneri, and Escherichia coli. J. Bacteriol. 177, 4097-4104 (1995).

7. Zhao, B. \& Houry, W. A. Acid stress response in enteropathogenic gammaproteobacteria: an aptitude for survival. Biochem. Cell Biol. 88, 301-314 (2010).

8. Sen, H. et al. Structural and functional analysis of the Escherichia coli acidsensing histidine kinase EvgS. J. Bacteriol. 199, e00310-e00317 (2017).

9. Hersh, B. M., Farooq, F. T., Barstad, D. N., Blankenhorn, D. L. \& Slonczewski, J. L. A glutamate-dependent acid resistance gene in Escherichia coli. J. Bacteriol. 178, 3978-3981 (1996).

10. De Biase, D., Tramonti, A., Bossa, F. \& Visca, P. The response to stationaryphase stress conditions in Escherichia coli: role and regulation of the glutamic acid decarboxylase system. Mol. Microbiol. 32, 1198-1211 (1999).

11. Iyer, R., Williams, C. \& Miller, C. Arginine-agmatine antiporter in extreme acid resistance in Escherichia coli. J. Bacteriol. 185, 6556-6561 (2003).

12. Soksawatmaekhin, W., Kuraishi, A., Sakata, K., Kashiwagi, K. \& Igarashi, K. Excretion and uptake of cadaverine by $\mathrm{CadB}$ and its physiological functions in Escherichia coli. Mol. Microbiol. 51, 1401-1412 (2004).

13. Richard, H. \& Foster, J. W. Escherichia coli glutamate- and argininedependent acid resistance systems increase internal $\mathrm{pH}$ and reverse transmembrane potential. J. Bacteriol. 186, 6032-6041 (2004).

14. Zhang, M. et al. A genetically incorporated crosslinker reveals chaperone cooperation in acid resistance. Nat. Chem. Biol. 7, 671-677 (2011).

15. Mujacic, M. \& Baneyx, F. Chaperone Hsp31 contributes to acid resistance in stationary-phase Escherichia coli. Appl. Environ. Microbiol. 73, 1014-1018 (2007).

16. Tramonti, A., De Canio, M. \& De Biase, D. GadX/GadW-dependent regulation of the Escherichia coli acid fitness island: transcriptional control at the gadY-gadW divergent promoters and identification of four novel $42 \mathrm{bp} \mathrm{GadX/GadW-specific} \mathrm{binding} \mathrm{sites.} \mathrm{Mol.} \mathrm{Microbiol.} \mathrm{70,} \mathrm{965-982}$ (2008). 
17. Seo, S. W., Kim, D., O'Brien, E. J., Szubin, R. \& Palsson, B. O. Decoding genome-wide GadEWX-transcriptional regulatory networks reveals multifaceted cellular responses to acid stress in Escherichia coli. Nat. Commun. 6, 7970 (2015).

18. Harden, M. M. et al. Acid-adapted strains of Escherichia coli K-12 obtained by experimental evolution. Appl. Environ. Microbiol. 81, 1932-1941 (2015).

19. Krulwich, T. A., Sachs, G. \& Padan, E. Molecular aspects of bacterial pH sensing and homeostasis. Nat. Rev. Microbiol. 9, 330-343 (2011).

20. Pienaar, J. A., Singh, A. \& Barnard, T. G. Acid-happy: survival and recovery of enteropathogenic Escherichia coli (EPEC) in simulated gastric fluid. Micro. Pathog. 128, 396-404 (2019).

21. Kaur, P. \& Asea, A. Loss of biofilm formation in an emerging foodborne pathogen Enteroaggregative Escherichia coli (EAEC) under acid stress. J. Cell Sci. Ther. 8, 260 (2017).

22. Small, P., Blankenhorn, D., Welty, D., Zinser, E. \& Slonczewski, J. L. Acid and base resistance in Escherichia coli and Shigella flexneri: role of rpoS and growth pH. J. Bacteriol. 176, 1729-1737 (1994).

23. Wang, H. \& Cronan, J. E. Only one of the two annotated Lactococcus lactis $f a b G$ genes encodes a functional $\beta$-ketoacyl-acyl carrier protein reductase. Biochemistry 43, 11782-11789 (2004).

24. Brown, J. L., Ross, T., McMeekin, T. A. \& Nichols, P. D. Acid habituation of Escherichia coli and the potential role of cyclopropane fatty acids in low $\mathrm{pH}$ tolerance. Int. J. Food Microbiol. 37, 163-173 (1997).

25. Keweloh, H., Diefenbach, R. \& Rehm, H. Increase of phenol tolerance of Escherichia coli by alterations of the fatty acid composition of the membrane lipids. Arch. Microbiol. 157, 49-53 (1991).

26. Fozo, E. M. \& Quivey, R. G. Jr Shifts in the membrane fatty acid profile of Streptococcus mutans enhance survival in acidic environments. Appl. Environ. Microbiol. 70, 929-936 (2004).

27. Quivey, R. G. Jr, Faustoferri, R., Monahan, K. \& Marquis, R. Shifts in membrane fatty acid profiles associated with acid adaptation of Streptococcus mutans. FEMS Microbiol. Lett. 189, 89-92 (2000).

28. Cao, Y. J., Yang, J. M., Xu, X., Liu, W. \& Xian, M. Increasing unsaturated fatty acid contents in Escherichia coli by coexpression of three different genes. Appl. Microbiol. Biotechnol. 87, 271-280 (2010).

29. De Wulf, P., McGuire, A. M., Liu, X. \& Lin, E. C. Genome-wide profiling of promoter recognition by the two-component response regulator CpxR-P in Escherichia coli. J. Biol. Chem. 277, 26652-26661 (2002).

30. Snyder, W. B. \& Silhavy, T. J. Beta-galactosidase is inactivated by intermolecular disulfide bonds and is toxic when secreted to the periplasm of Escherichia coli. J. Bacteriol. 177, 953-963 (1995).

31. DiGiuseppe, P. A. \& Silhavy, T. J. Signal detection and target gene induction by the CpxRA two-component system. J. Bacteriol. 185, 2432-2440 (2003).

32. Henry, M. F. \& Cronan, J. E. Jr. Escherichia coli transcription factor that both activates fatty acid synthesis and represses fatty acid degradation. J. Mol. Biol. 222, 843-849 (1991).

33. Feng, Y. \& Cronan, J. E. Escherichia coli unsaturated fatty acid synthesis: complex transcription of the fabA gene and in vivo identification of the essential reaction catalyzed by FabB. J. Biol. Chem. 284, 29526-29535 (2009).

34. Campbell, J. W. \& Cronan, J. E. Jr. Escherichia coli FadR positively regulates transcription of the $f a b B$ fatty acid biosynthetic gene. J. Bacteriol. 183, 5982-5990 (2001).

35. Vogt, S. L. \& Raivio, T. L. Just scratching the surface: an expanding view of the Cpx envelope stress response. FEMS Microbiol. Lett. 326, 2-11 (2012).

36. Raivio, T. L. Everything old is new again: an update on current research on the Cpx envelope stress response. Biochim. Biophys. Acta 1843, 1529-1541 (2013).

37. Fleischer, R., Heermann, R., Jung, K. \& Hunke, S. Purification, reconstitution, and characterization of the CpxRAP envelope stress system of Escherichia coli. J. Biol. Chem. 282, 8583-8593 (2007).

38. Perez, J. C. \& Groisman, E. A. Acid pH activation of the PmrA/PmrB two component regulatory system of Salmonella enterica. Mol. Microbiol. 63, 283-293 (2007).

39. Perez, J. C. et al. Evolution of a bacterial regulon controlling virulence and $\mathrm{Mg}^{2+}$ homeostasis. PLoS Genet 5, e1000428 (2009).

40. Lioliou, E. E. et al. Phosphorylation activity of the response regulator of the two-component signal transduction system AtoS-AtoC in E. coli. Biochim. Biophys. Acta 1725, 257-268 (2005).

41. Fritz, R., Stiasny, K. \& Heinz, F. X. Identification of specific histidines as $\mathrm{pH}$ sensors in flavivirus membrane fusion. J. Cell Biol. 183, 353-361 (2008).

42. Lee, D. et al. RAP uses a histidine switch to regulate its interaction with LRP in the ER and Golgi. Mol. Cell 22, 423-430 (2006).

43. Thompson, A. N., Posson, D. J., Parsa, P. V. \& Nimigean, C. M. Molecular mechanism of $\mathrm{pH}$ sensing in KcsA potassium channels. Proc. Natl Acad. Sci. USA 105, 6900-6905 (2008).

44. Laroche, C., Beney, L., Marechal, P. A. \& Gervais, P. The effect of osmotic pressure on the membrane fluidity of Saccharomyces cerevisiae at different physiological temperatures. Appl. Microbiol. Biotechnol. 56, 249-254 (2001).
45. Sturr, M. G. \& Marquis, R. E. Comparative acid tolerances and inhibitor sensitivities of isolated F-ATPases of oral lactic acid bacteria. Appl. Environ. Microbiol. 58, 2287-2291 (1992).

46. Mahon, M. J. pHluorin2: an enhanced, ratiometric, $\mathrm{pH}$-sensitive green florescent protein. Adv Biosci. Adv. Biosci. Biotechnol. 2, 132-137 (2011)

47. Hickey, E. W. \& Hirshfield, I. N. Low-pH-induced effects on patterns of protein synthesis and on internal pH in Escherichia coli and Salmonella typhimurium. Appl. Environ. Microbiol. 56, 1038-1045 (1990).

48. Slonczewski, J. L., Rosen, B. P., Alger, J. R. \& Macnab, R. M. pH homeostasis in Escherichia coli: measurement by ${ }^{31} \mathrm{P}$ nuclear magnetic resonance of methylphosphonate and phosphate. Proc. Natl Acad. Sci. USA 78, 6271-6275 (1981).

49. Alvarez-Ordonez, A. et al. Acid stress management by Cronobacter sakazakii. Int. J. Food Microbiol. 178, 21-28 (2014).

50. Ragheb, M. N. et al. Inhibiting the evolution of antibiotic resistance. Mol. Cell 73, 157-165 e155 (2019).

51. Gorden, J. \& Small, P. L. Acid resistance in enteric bacteria. Infect. Immun. 61, 364-367 (1993).

52. Gilbert, R. J. \& Roberts, D. Food hygiene aspects and laboratory methods. PHLS Micorbiol. Dig. 3, 32-34 (1986).

53. Tong, W. et al. Biosynthetic pathway for acrylic acid from glycerol in recombinant Escherichia coli. Appl. Microbiol. Biotechnol. 100, 4901-4907 (2016).

54. Liu, C. et al. Functional balance between enzymes in malonyl-CoA pathway for 3-hydroxypropionate biosynthesis. Metab. Eng. 34, 104-111 (2016).

55. Ma, Y. \& Marquis, R. E. Thermophysiology of Streptococcus mutans and related lactic-acid bacteria. Antonie van. Leeuwenhoek 72, 91-100 (1997).

56. Aboulwafa, M. \& Saier, M. H. Jr Lipid dependencies, biogenesis and cytoplasmic micellar forms of integral membrane sugar transport proteins of the bacterial phosphotransferase system. Microbiology 159, 2213-2224 (2013).

57. Markevics, L. J. \& Jacques, N. A. Enhanced secretion of glucosyltransferase by changes in potassium ion concentrations is accompanied by an altered pattern of membrane fatty acids in Streptococcus salivarius. J. Bacteriol. 161, 989-994 (1985).

58. Chang, Y. Y. \& Cronan, J. E. Jr Membrane cyclopropane fatty acid content is a major factor in acid resistance of Escherichia coli. Mol. Microbiol. 33, 249-259 (1999).

59. Wang, A. Y., Grogan, D. W. \& Cronan, J. E. Jr Cyclopropane fatty acid synthase of Escherichia coli: deduced amino acid sequence, purification, and studies of the enzyme active site. Biochemistry 31, 11020-11028 (1992).

60. Prost, L. R. et al. Activation of the bacterial sensor kinase PhoQ by acidic $\mathrm{pH}$ Mol. Cell 26, 165-174 (2007).

61. Surmann, K., Cudic, E., Hammer, E. \& Hunke, S. Molecular and proteome analyses highlight the importance of the Cpx envelope stress system for acid stress and cell wall stability in Escherichia coli. Microbiologyopen 5, 582-596 (2016).

62. Weatherspoon-Griffin, N. et al. The CpxR/CpxA two-component system upregulates two Tat-dependent peptidoglycan amidases to confer bacterial resistance to antimicrobial peptide. J. Biol. Chem. 286, 5529-5539 (2011).

63. Bernal-Cabas, M., Ayala, J. A. \& Raivio, T. L. The Cpx envelope stress response modifies peptidoglycan cross-linking via the L,D-transpeptidase LdtD and the novel protein YgaU. J. Bacteriol. 197, 603-614 (2015).

64. Siryaporn, A. \& Goulian, M. Cross-talk suppression between the CpxA-CpxR and EnvZ-OmpR two-component systems in E. coli. Mol. Microbiol. 70, 494-506 (2008).

65. Stincone, A. et al. A systems biology approach sheds new light on Escherichia coli acid resistance. Nucleic Acids Res. 39, 7512-7528 (2011).

66. Chakraborty, S. \& Kenney, L. J. A new role of OmpR in acid and osmotic stress in Salmonella and E. coli. Front. Microbiol. 9, 2656 (2018).

67. Datsenko, K. A. \& Wanner, B. L. One-step inactivation of chromosomal genes in Escherichia coli K-12 using PCR products. Proc. Natl Acad. Sci. USA 97, 6640-6645 (2000).

68. Zhao, G., Weatherspoon, N., Kong, W., Curtiss, R. 3rd \& Shi, Y. A dual-signal regulatory circuit activates transcription of a set of divergent operons in Salmonella typhimurium. Proc. Natl Acad. Sci. USA 105, $20924-20929$ (2008).

69. Edwards, R. A., Keller, L. H. \& Schifferli, D. M. Improved allelic exchange vectors and their use to analyze 987P fimbria gene expression. Gene 207, 149-157 (1998).

70. Livak, K. J. \& Schmittgen, T. D. Analysis of relative gene expression data using real-time quantitative PCR and the $2^{-\Delta \Delta \mathrm{Ct}}$ Method. Methods 25, 402-408 (2001).

\section{Acknowledgements}

We thank Dr. Roy Curtiss III (University of Florida) for pRE112 and E. coli $\chi 7213$, Dr. Lixue Zhang (Qingdao University) for help on proteoliposome reconstruction, Dr. Qinggang Wang (Qingdao Institute of Bioenergy and Bioprocess Technology) for helpful discussion, and NBRP-E.coli at NIG for BW25113 strain. This study was 
financially supported by the NSFC (31722001 and 31670089), and Natural Science Foundation of Shandong Province (JQ201707).

\section{Author contributions}

G.Z. designed the experiments. Y.X., Z.Z., W.T., Y.S., Y.D., B.L., J.W., M.L., Y.W. and S.S performed the experiments. G.Z., M.X., Y.X. and Q.Q. analyzed the results. G.Z., M.X., Y.X. and Q.Q. wrote the manuscript. All authors edited the manuscript before submission.

\section{Competing interests}

The authors declare no competing interests.

\section{Additional information}

Supplementary information is available for this paper at https://doi.org/10.1038/s41467020-15350-5

Correspondence and requests for materials should be addressed to M.X. or G.Z.

Peer review information Nature Communications thanks Daniela De Biase, Peter Lund and the other, anonymous, reviewer for their contribution to the peer review of this work. Peer reviewer reports are available.
Reprints and permission information is available at http://www.nature.com/reprints

Publisher's note Springer Nature remains neutral with regard to jurisdictional claims in published maps and institutional affiliations.

\section{(c) (i)}

Open Access This article is licensed under a Creative Commons Attribution 4.0 International License, which permits use, sharing, adaptation, distribution and reproduction in any medium or format, as long as you give appropriate credit to the original author(s) and the source, provide a link to the Creative Commons license, and indicate if changes were made. The images or other third party material in this article are included in the article's Creative Commons license, unless indicated otherwise in a credit line to the material. If material is not included in the article's Creative Commons license and your intended use is not permitted by statutory regulation or exceeds the permitted use, you will need to obtain permission directly from the copyright holder. To view a copy of this license, visit http://creativecommons.org/ licenses/by/4.0/.

(C) The Author(s) 2020 